

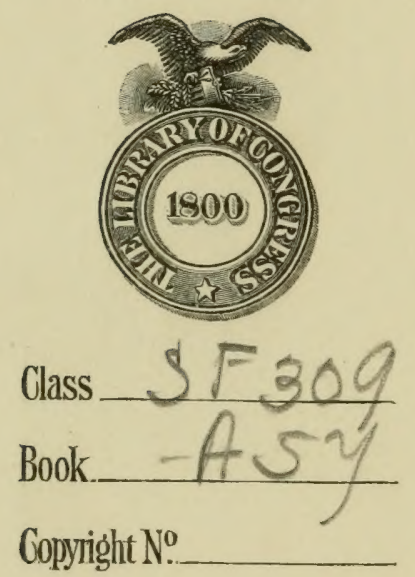

COPYRIGHT DEPOSK. 







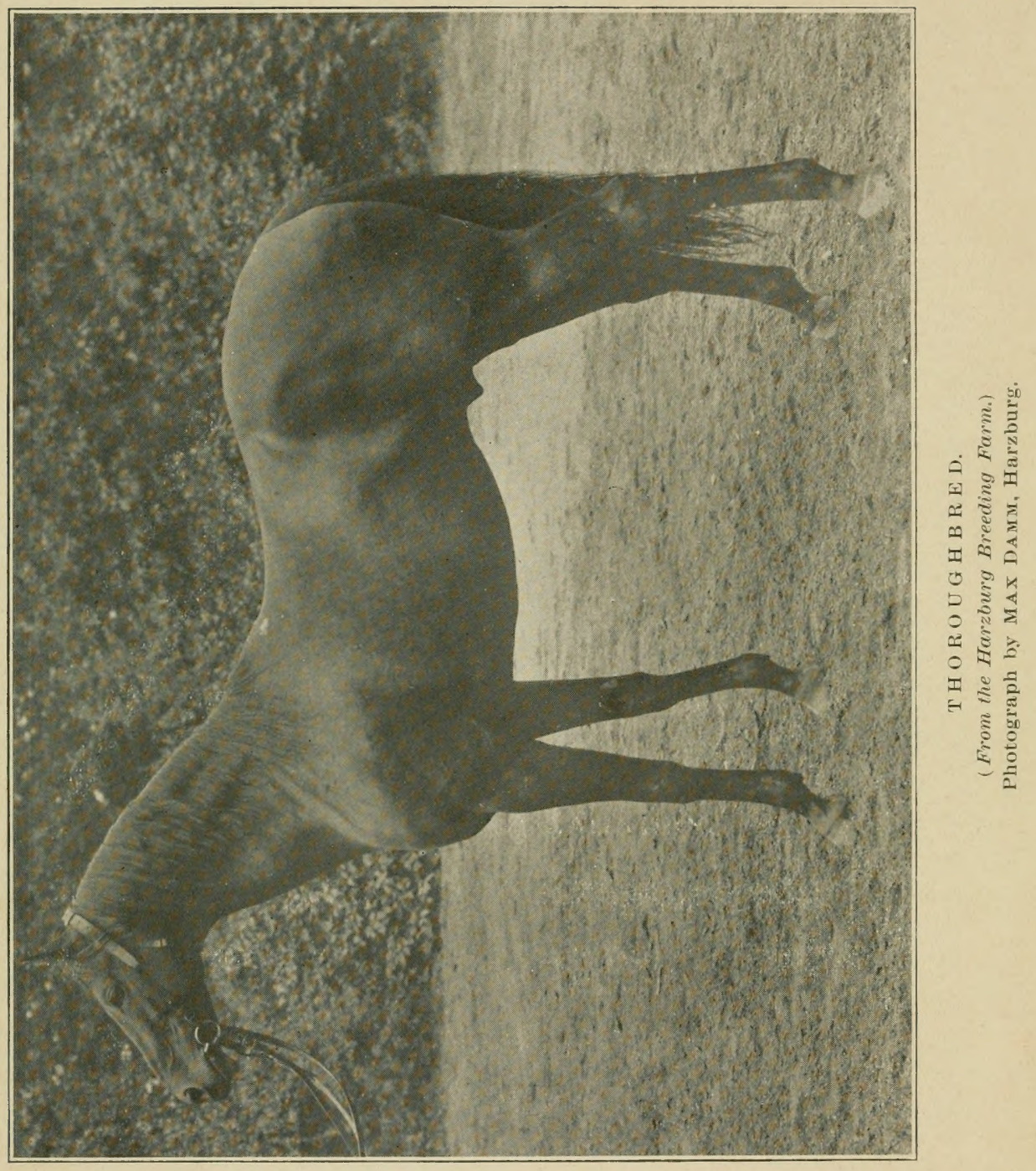




\title{
HORSES AND RIDING
}

BV

\author{
EDWARD L. ANDERSON
}

AUTHOR OF

“Modern Horsemanship," "Curb, Snaffle and Spur,"

"Vice in the Horse", Etc., Etc.

Illustrated with Forty Half Tone Plates.

U. S. CAVALRY ASSOCIATION,

Fort Leavenworth, Kansas.

1909. 


$$
\begin{aligned}
& 5<309 \\
& i^{2} 57
\end{aligned}
$$

KETCHESON PPINTING COMPANY, I,EA VEN WORTH, KANSAS.

(C) Aug. 10,1909
Cla. A. 244667
AUG 121909




\title{
HORSES AND RIDING.
}

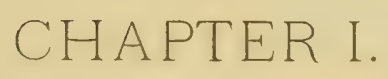

BREEDS AND FAMILIES OF HORSES

\author{
SUITABLE FOR RIDING.
}

N AUREGGIO, the authority on this subject in France, mounted than those of any other country. The chargers so highly commended are Irish weight-carrying hunters, and cost from $\$ 400$ upwards. But there is no such breed or even family by which to identify these horses. They are for the most part nearly thoroughbreds; but, until a strain is established, an excellent result of a cross is really an accident, and the good qualities of an Irish hunter are due partly to the judgment of the breeder, partly to climate, and partly to early training given them in leaping and in climbing obstacles, not to speak of discretion in buying. At home they are never well trained saddle horses; but in the hands of Italian horsemen they soon become thorough chargers capable of wonderful exertions in crossing a cramped or difficult country, and 
there is no better horse for heavy weights than the best of one of these fortunate chances.

Occasionally the thoroughbred makes a horse that may be suitable for any purpose, but the blood horse has not the agility and pliancy that should characterize the perfect hack, hunter or charger and it is too apt to trip in the walk and in the slow trot. The writer has trained a number of thoroughbreds and usaully found them docile and submissive,

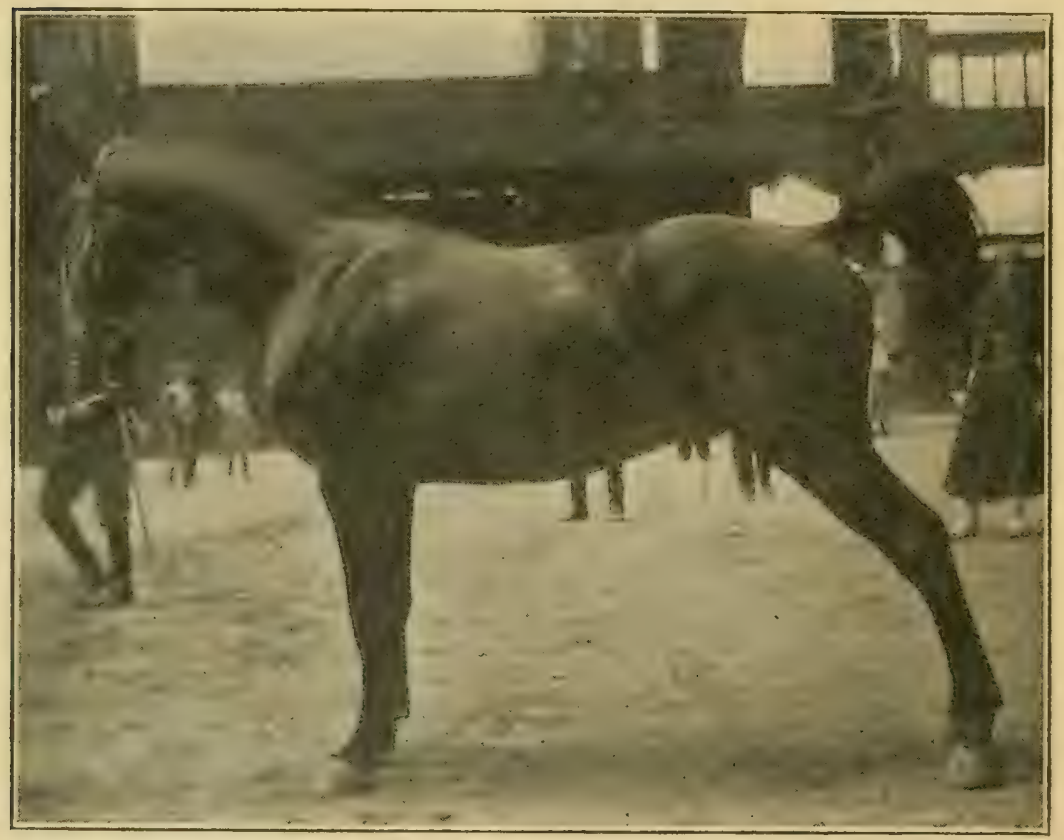

ENDORÉ. ANGLO-NORMAND.

Property:of Raoul Balliere, Caen, Normandy. The fnest horse in France for Cavalry. Photographed by the Author.

even such as have been taken from the racing stables; but their strides are too long and too close to the ground for safety, although collecting the forces of the extremities temporarily overcomes these faults in the hands of a competent rider. M. James Fillis and the ecuyers and stallmeisters of the riding academies may select the blood horse, but this is written for general riders, and not for the skillful.

Although there is no rule regarding the shares of strains 
in the Anglo-Normand beyond the requirement that it shall have at least half of the blood of the thoroughbred, and many have a very liberal half, it may be accounted as a distinct breed owing to the homogenity due to what horsemen call the prepotency of the Normand side. The large horse represented by the photographs of this work is an Anglo. Normand from the stud farm of Annecy. The Anglo-Normand is the handsomest of the large horses and has many admirable qualities.

The Tarbais, or horse of Tarbes, was originally a cross of the Arab upon the horse of the Midi, which was in itself

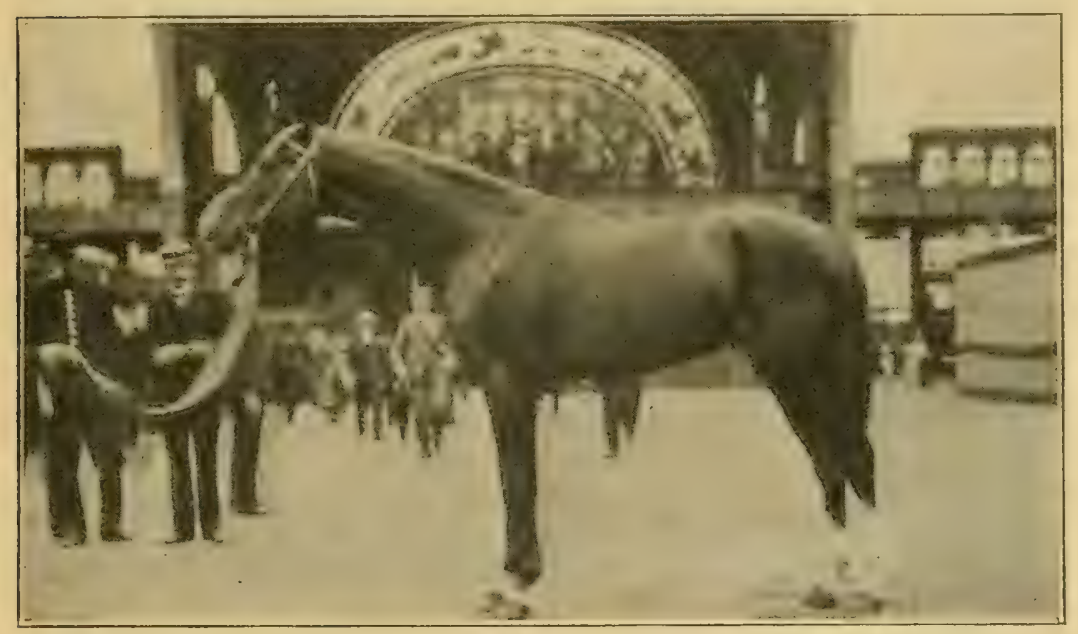

ANGLO-A RAB.

Purchased by the Italian goverment.

Photograph by the Author.

largeily of Eastern blood, the product being a small animal of great stamina and activity. But the present Tarbais of the government farms has a large infusion of the English blood horse, although in the south of France the smaller horse, Tarbais, Anglo-Arab, and even the Arab, is held in high estimation. The horse I rode for the gallop-change, the halt in the gallop, etc., is registered in the stud book as Anglo-Arab qualifié; that is, it had some of the strains in its veins of the old stock of the south of France as well as those of its English and Eastern ancestors. 
The more highly bred of the typical Hungarian horses are nearly thoroughbred with a dash of Eastern blood introduced more recently than the similar strain that is in the make up of the English race horse. The Hungarian is held in high esteem for light cavalry and for riders of medium weight. It has great powers of resistance against changes of climate and against long continued fast work, for which rea. sons it is generally considered the most valuable of the smaller breeds. A cavalry officer who has had a very wide experience with horses of many varieties told me that he

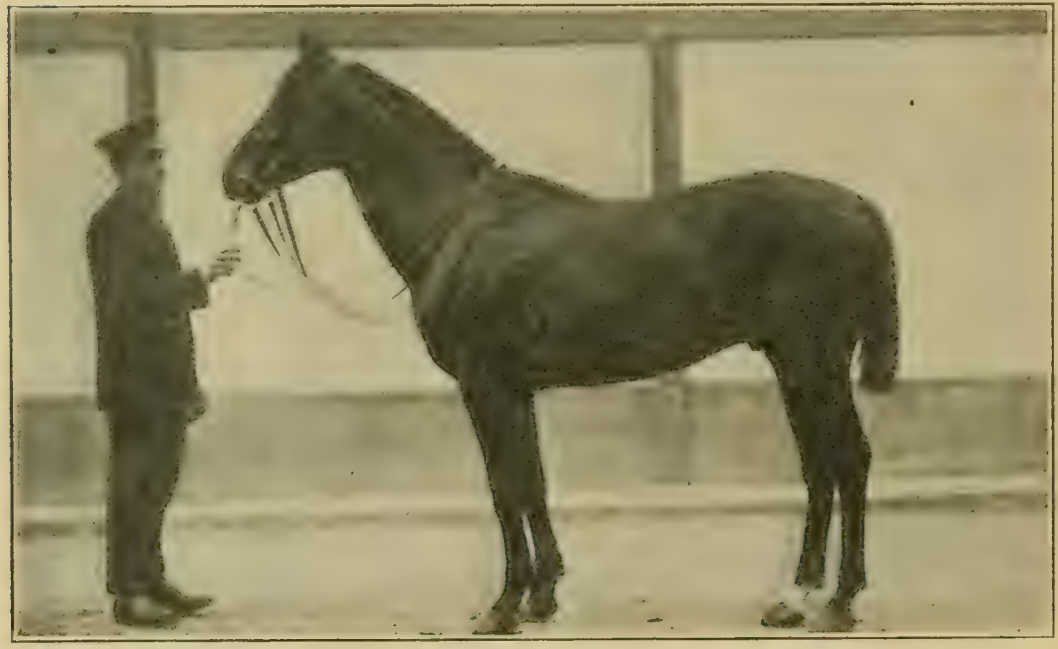

ANGLO-ArAB。(Qualifié).

Property of the Author. Photograph by the Author.

preferred horses of this breed to any others, and that while they were at first difficult to train they became very trustworthy after they had given submission.

The Barb was formed originally by a cross of the horse of northern Europe, introduced by the Teutonic invaders, upon the horse of northern Africa. It was long celebrated for its docility and for its hardiness. These qualities are said to be retained by the very "mixed" lot that are still called Barbs, into which Arab and English strains have been introduced more or less. Of course there have been, from very early 
times, numbers of desert bred horses, or of their descendants, brought into Africa, and many of these have been kept more or less pure. I feel rather certain that the "Barb" an. cestor of our race horse was one of these Arabs.

In Algiers the French government has endeavored to reëstablish the best form of the horse of northern Africa by

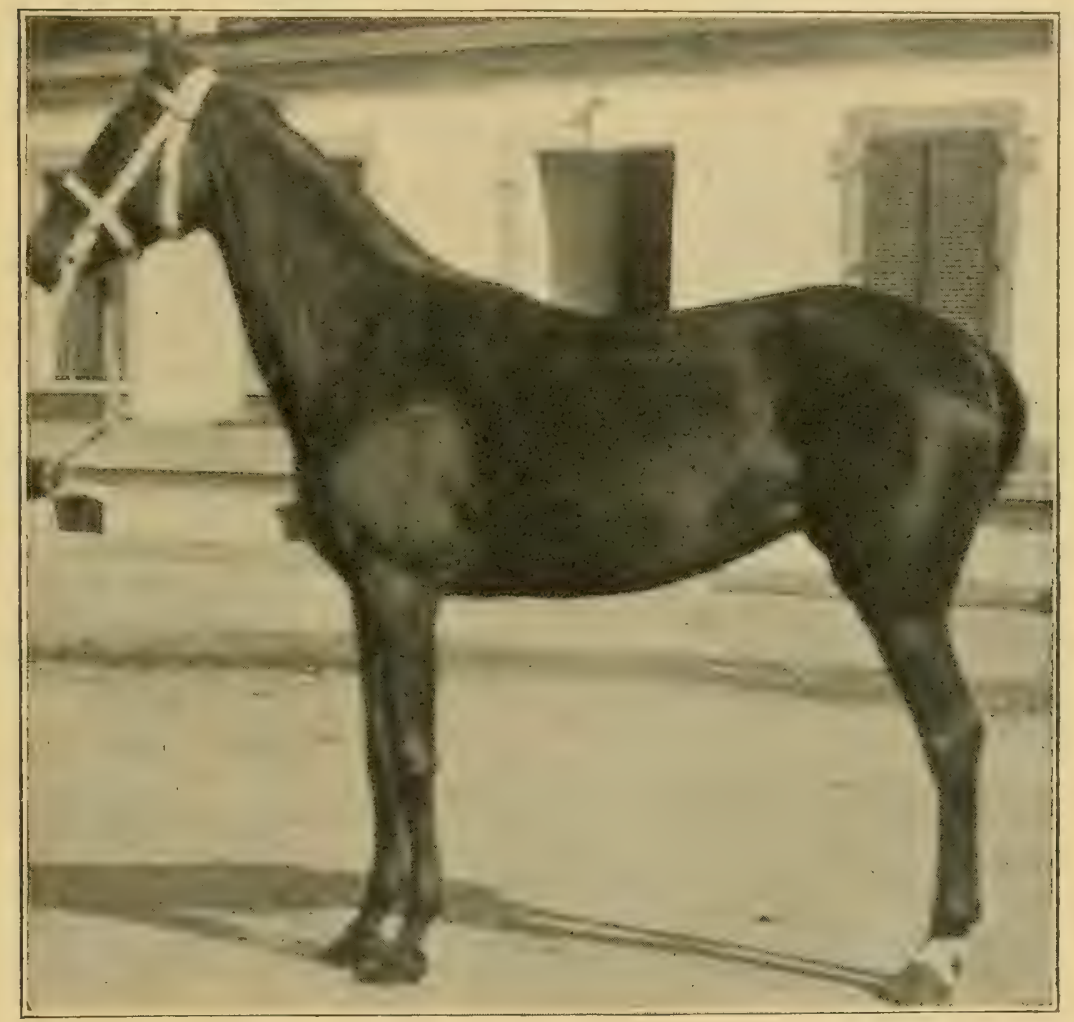

HUNGARIAN

From the Zechy Breeding Farm. Photograph by the Author.

forming breeding farms and by arranging a stud.book in which the pedigree may be entered and preserved.

For grace, beauty, temperament, and every other good quality that a riding horse should possess there is no breed, family or strain superior to the Denmarks of the Blue-grass region of Kentucky. They may not have the speed of the 
blood horse, the resistance of the Barb, or the stamina of the Hungarian, but for confidential use they are incomparable. The inbred Denmarks, and the highest authorities say that a saddle horse cannot have too many strains of the celebrated ancestor, must be nearly thoroughbred with, almost eliminated, crosses of the Canadian pacer and the Morgan trotter.

It will be seen that nearly every horse that is held in high consideration in Europe or in America has a very large pro-

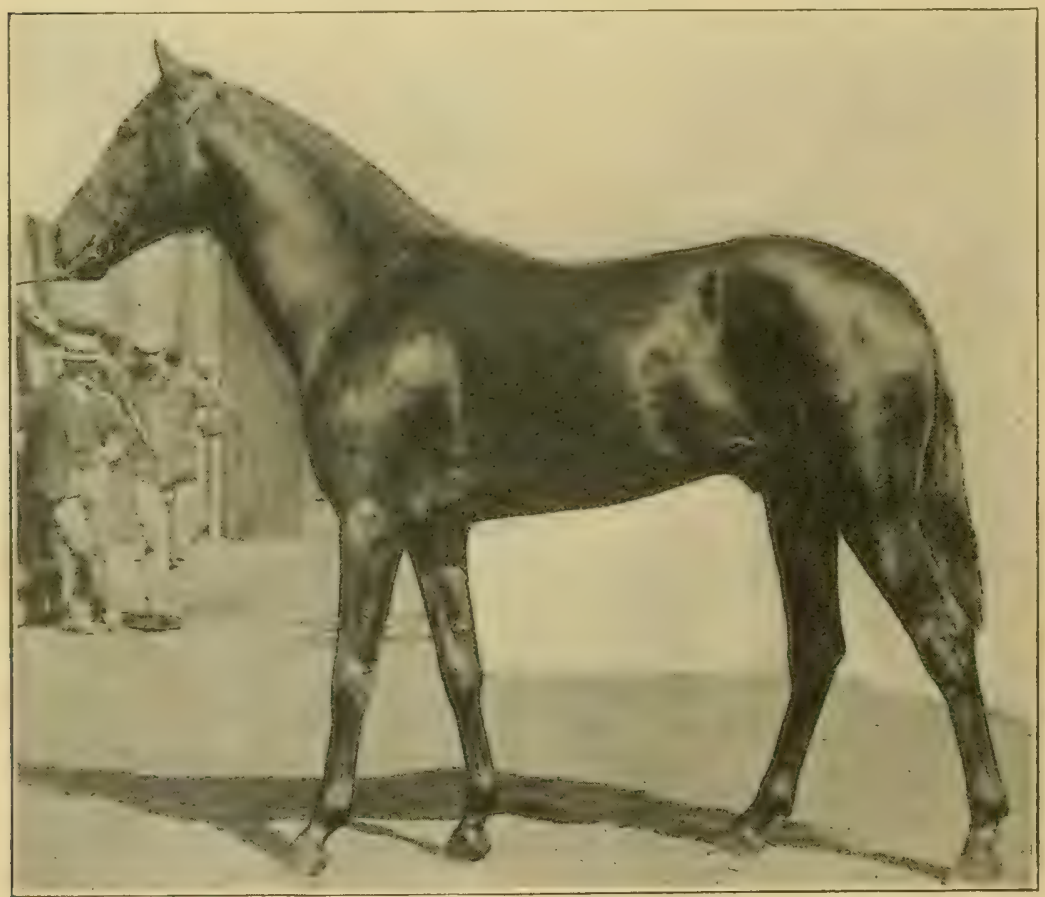

BARB. AMOURANIA.

Algerian Stud Book. Photograph by J. Delton, Paris.

portion of the blood of the thoroughbred, and it is certain that no other breed has such power of transmitting its good qualities, or has so many good qualities to transmit. The writer is not prepared to say that the race horse is deterio. rating in the efforts of breeders to produce "sprinters" for short distances, but such competitions as the three and four mile heat races in which Lexington, Asteroid, Kentucky and 
many other horses of the middle of the nineteenth century took part are no longer favored, and it might be difficult to find rivals should one of the old four-milers reappear with "Uncle Anson" responsible for its condition.

As every thoroughbred must trace its ancestry back to one of three eastern horses, Darley's Arabian, Byerly's Turk or Godolphin's Barb, and has in fact the blood of all three in its veins, it is self-evident that the desert horse has had much to do in bringing a refining influence upon some coarser but more useful breed that had existed in England previous to

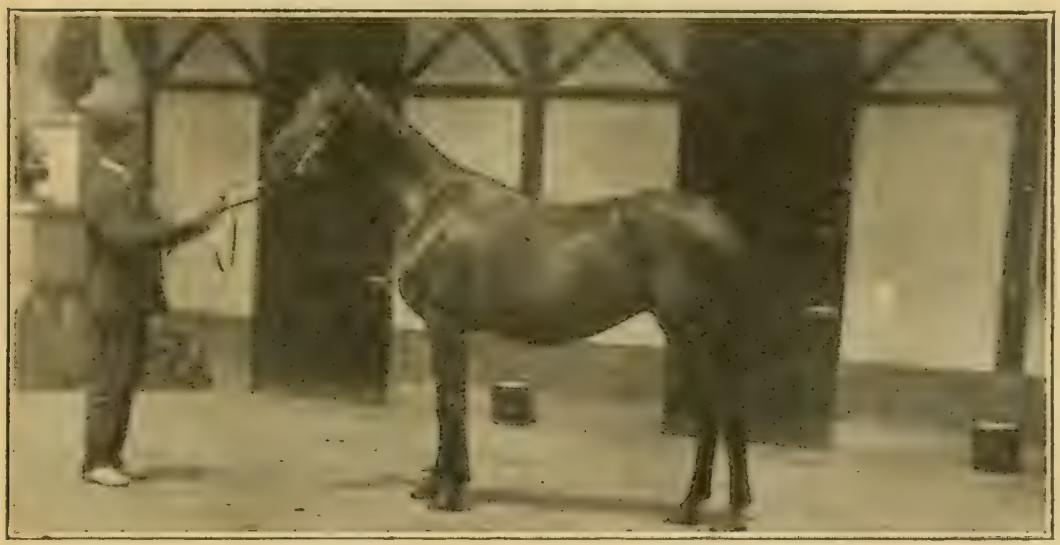

PURE BLood ARAB MARE. KAIIIFA II.

Registered in French Stud Book. Seventh in descent from the tents of Nedy. Photograph by the Author.

our history of the matter. But whatever may have been the true origin of the thoroughbred, it has been for more than a a century the noblest race of its species, and it is infinitely superior to any horse that has ever appeared in the Orient.

It remains to be said, however, that any strong horse may be made, by schooling, a very agreeable riding horse, even when it has slight defects in conformation, for such may be nullified by careful handling. Indeed the most perfectly formed horse must be rough and awkward under a rider until it has been given, or has acquired an artificial bearing 
suitable to the unnatural conditions of carrying a burthen and of having its impulses checked, hampered and harassed by bit and spurs.

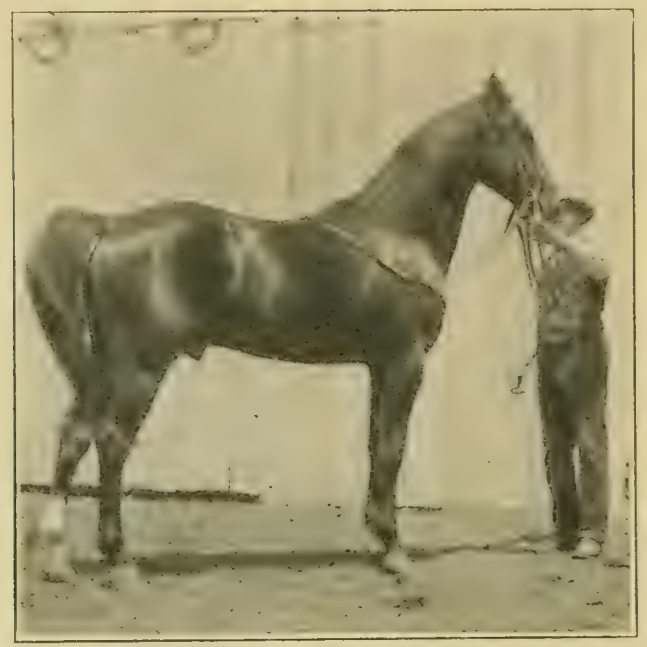

AMERIOAN SADDLE HORSE. STERIING CHIEF.

Property of Oolonel J. T. Woodford. Photograph by the Author. 
CHAPTER II.

\section{A FEW GENERAL REMARKS UPON RIDING.}

I accept, without reservation, the saying of that fine horseman, Colonel Vigier von Steinbrugge, that no one may be considered a rider who does not understand the principles of Baucher. But Baucher's meanings are often so obscure as to require explanation, and, further, in his later writings he carried theories too far for practical use.

In simple but comprehensive language Baucher's idea was to obtain complete and instantancous obedience from the horse by the cultivation of the instinctive muscular actions which follow the application of the hand and heel. This formula was a stroke of genius, and proved Baucher to have been the greatest horsemen that the world has seen. Unfortunately for the art his contemporary, Comte d'Aure, had the ear of France, and was the director of the L'école d'Application de Cavalerie at Saumur, and this opposition to the finished method of his rival has had in some ways a bad influence upon general horsemanship. I think that I can truthfully say that I am familiar with nearly every work and text book on riding that carries any weight, from the days of the pupils of Pignatelli down to the present time; that is, for about four hundred years, and I do not hesitate to express the opinion that many of the manuals of the great armies of Europe have always been, and still are, full of errors and contradictions. The prime faults being in the rules for demanding the gallop, and for making the turns and wheels; if these are not evident to any one who reads the works in question it is not worth while discussing the matter, although I may explain for the uninitiated, that their rules for demanding the gallops among other fallacies would tend to make the horse false in the changes of direction in that pice. The only book pub. lished recently in a foreign language that I can recommend is that of Mr. James Fillis which appeared, I have a right to remark, four years after I had properly and fully explained the gallop-change in the 1886 edition of "Modern Horse- 
manship." It must be noted, however, that although Fillis is evidently a follower of Baucher his criticisms are really aimed at some very poor drawings which were intended to illustrate the work, for Baucher always deprecated the lowering of the head of the horse and the custom of permitting

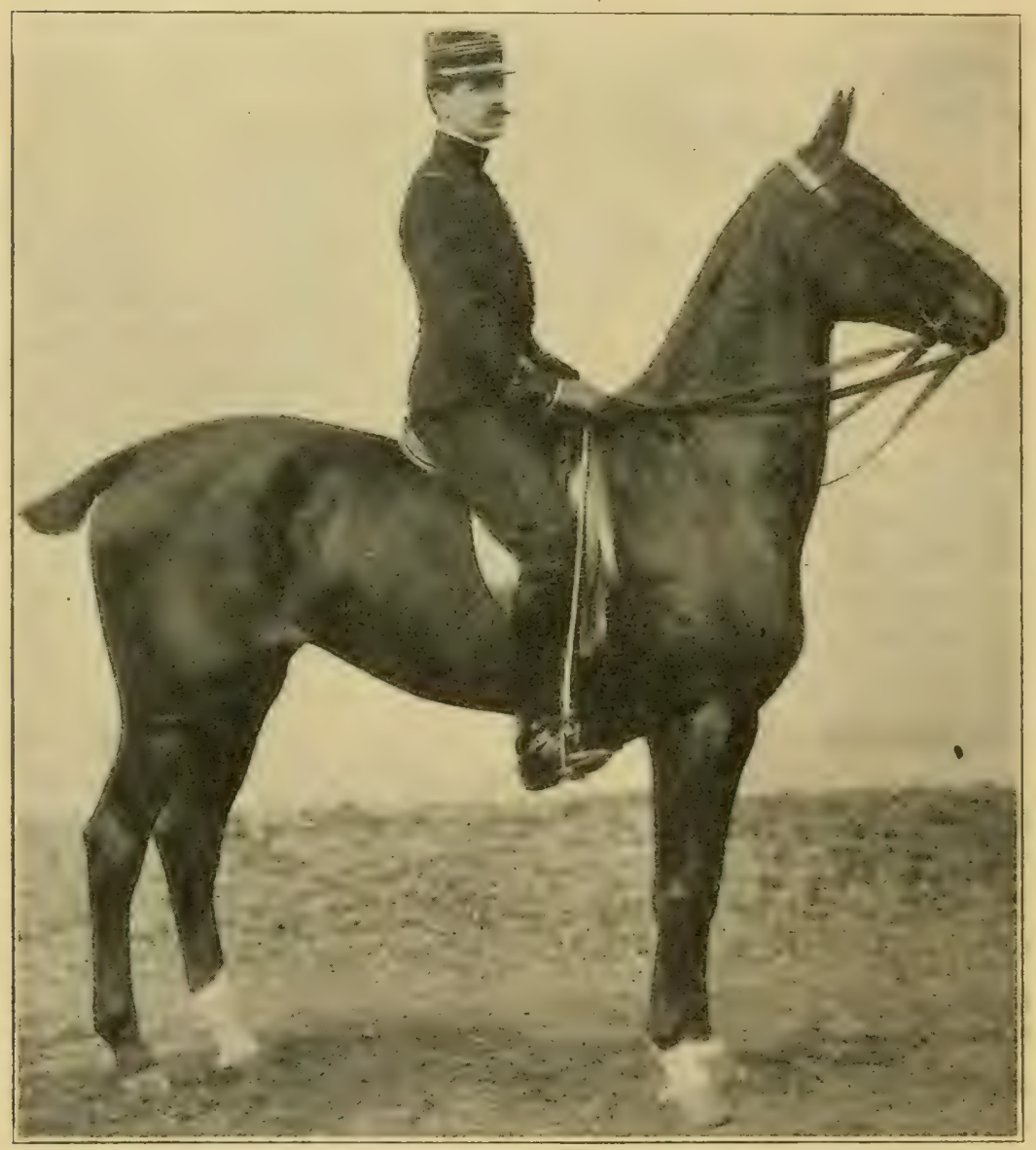

Captain Crotsse of the Frenoit Army, on Conspiration.

Winner in 1908 at Paris, Rome and Brussels. Photograph by J. Delton, Paris.

the face to make less then a right angle with the plane of movement, and in the carefully prepared portrait of the master upon Partisan, the horse is represented as carrying its head sufficiently high. 
When a horse will move smoothly and evenly under its rider we are approaching that condition of the union of the weights and forces of the extremities known as the equilibrium. Of course in a state of perfect equilibrium there would be no motion, but for safety, for obedience and for cadenced action there must be a certain approach to the union and balance of the forces under the rider, and this takes place

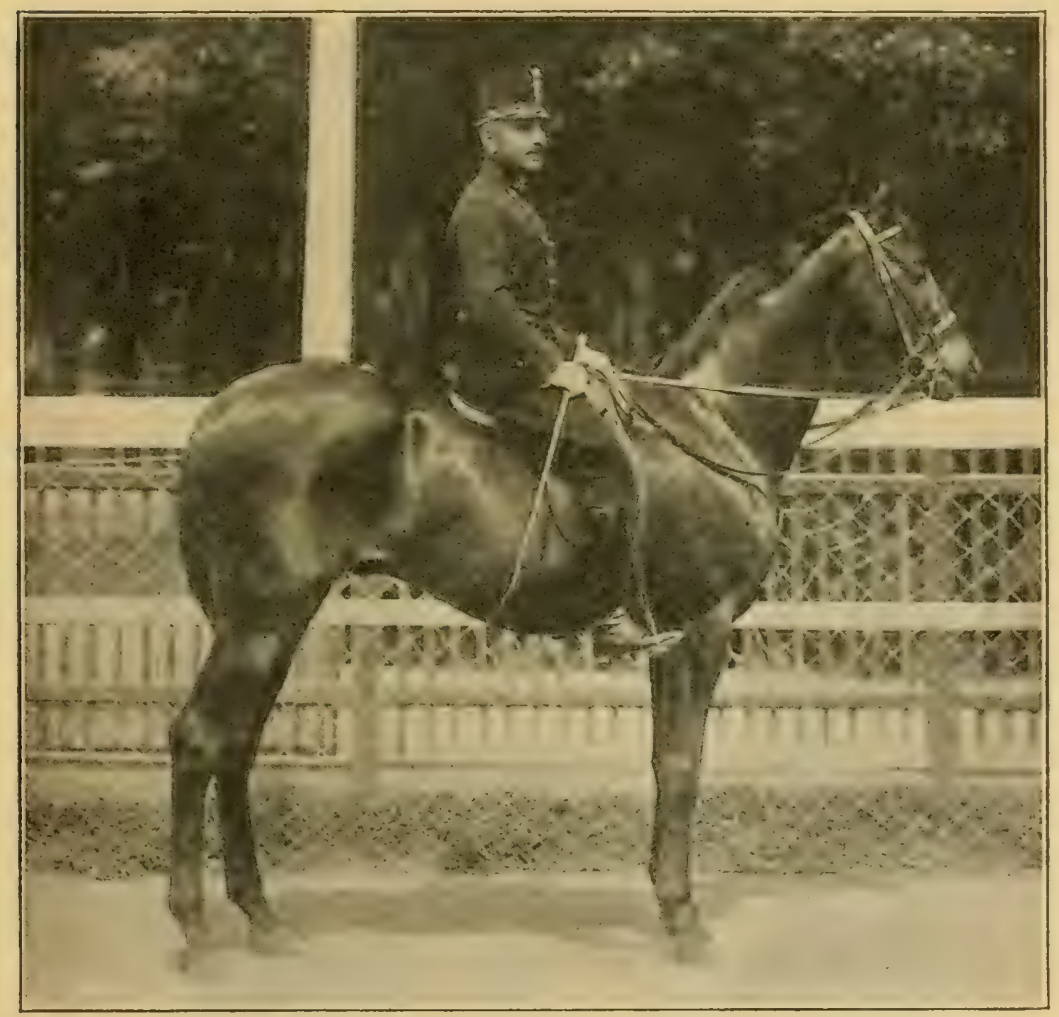

CAPTAIN VON PONGRATZ

One of the flnest horseman of the Austrian Army. Photograph by A. Huber, Vienna.

whenever a horse is pleasant to ride, whether the man knew or did not know how the affair was accomplished. It is the "fad" nowadays, of pretenders to horsemanship, to let the horse go along in a disunited, slovenly manner; this is not only an ugly sight but it is dangerous for those who practice 
it. This mode of riding may be seen in Rotten-row, in Central Park, and, more especially, on the ride of the Avenue du Bois in Paris; but real horsemanship is exhibited in the Concours of Paris, of Brussels and of Vienna by such riders as MM. Leclerc, Liebenstein, Crousse, von Pongratz and by hundreds of other gentlemen of intelligence and skill who maintain the art in its integrity, for horsemanship is an art that requires study and practice for any proficiency.

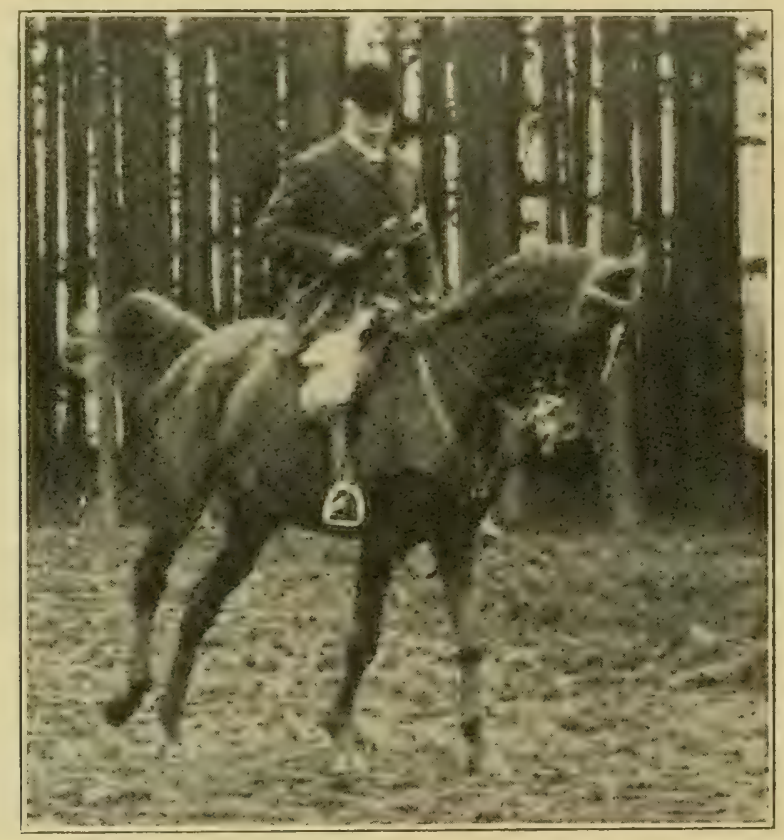

GENERAL VON MITZLAFF.

Superintendent of the Cavalry School at Hanover. Photograph by Berger, Hanover.

Owing to certain reasons "Charre," the Anglo-Arab which was employed for the larger number of photographs in this book, had many interruptions in its training previously to its appearance before the camera; and it had been ridden in the open only some six weeks before it was ready to make the gallop-change and other movements, on the Normandy coast, as are shown by the pictures. The Anglo-Normand, trained in Switzerland, had even less attention given to its 
handling before it was ready for the travers gallop and other movements in that pace, for it took readily to the gallop.

The education of a horse can be carried on much more rapidly by the work on foot, as suggested by Baucher, than

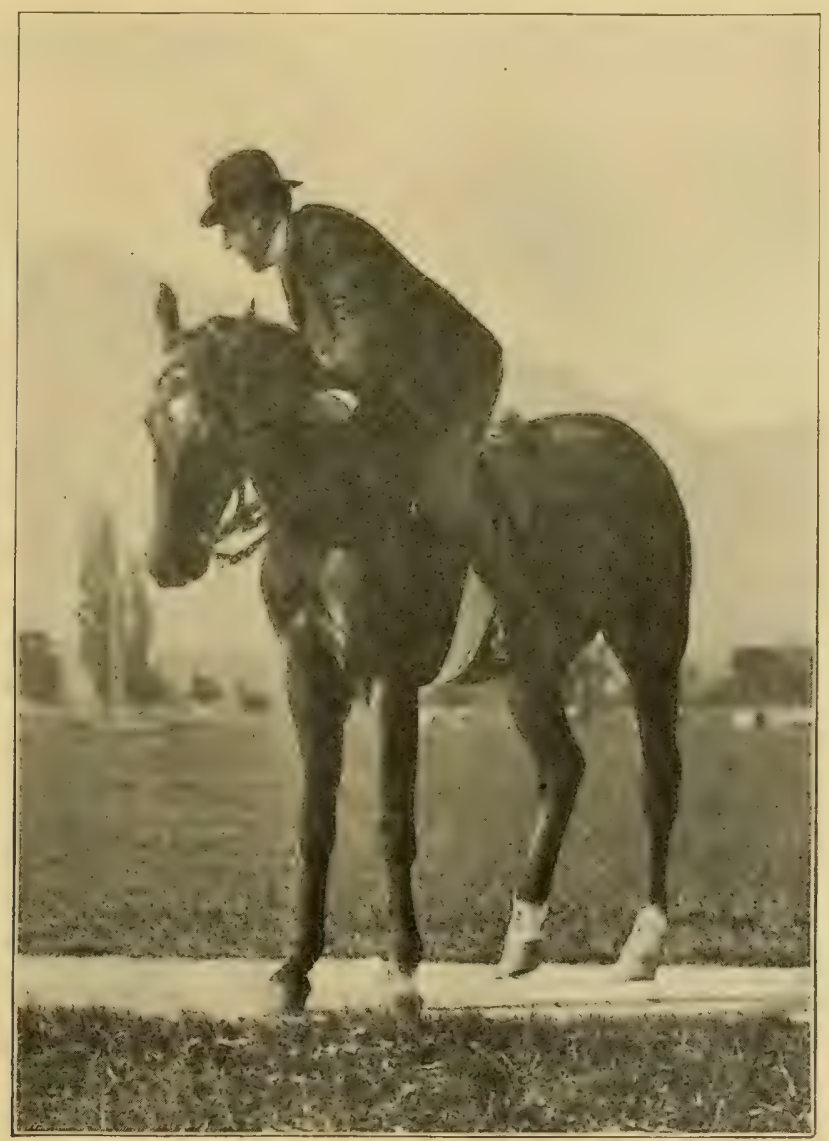

VAULTING INTO THE SADDLE.

Photograph by M. F. A.

by the mounted exercises alone; and I believe that a horse could be completely trained without the rider mounting, although I have never quite proved that to myself, as I have always been too desirous of getting upon the back of the 
animal I had in hand in order that I might have the feel of the saddle.

I once wrote a little work on "'The Simple Art of Horsemanship," but before it reached the hands of an editor I found that a lady had used the same title in a periodical, and so my paper, in Country Life in America, was entitled "The Whole Art of Horsemanship." The art is in fact extremely simple, and in half an hour a complete knowledge of its

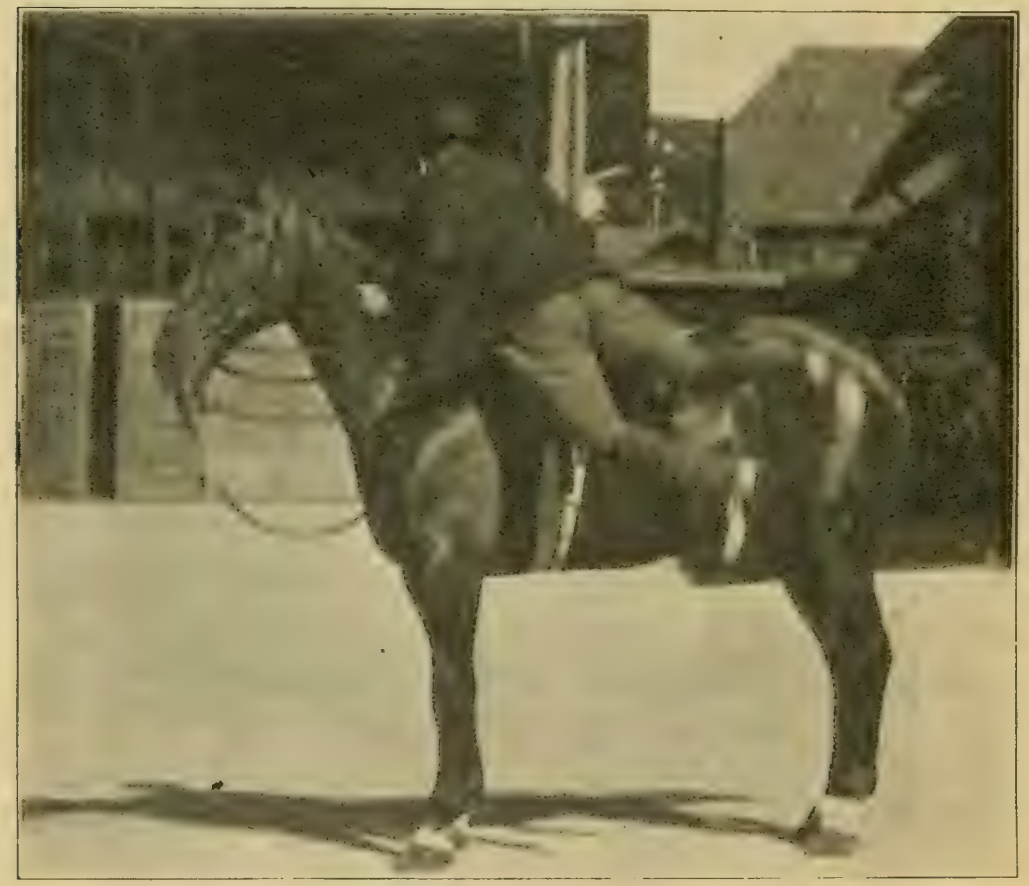

DIBYOONTING.

Photograph by Dorothy Woods.

principles should be acquired by any one who has a taste for riding. It takes long practice to make a good rider, and aptitude is necessary for excellence; it is certain that the longer a beginner sticks to the walk, and studies his position, the better and stronger will be his seat. I think that proficient horseman, de Bussigny, was jesting when he said that it required fifteen years at the walk to give a perfect seat on the 
horse; but fifteen days will not bring it as many tyros seem to believe.

It was as long ago as 1857 that Henri Franconi taught me the method of Baucher; notwithstanding, I find that I ride as strongly as I ever did, and take as much pleasure in training young horses as when I began the fascinating work; indeed, from constant practice in riding and in moderate gymnastics I am as active as one could wish, and I can vault into the saddle or leap to the ground without difficulty. It should be understood that I am an amateur, having no saddle horses for sale; when an animal proves unsuitable it is sent to the auctioneer and sold anonymously, never to be heard of again. The echo of a horse deal is seldom agreeable.

I wish to repeat what I have often said, that there:is neither formidable nor esoteric knowledge in the training of a horse. If a proper method is employed pupil and master proceed without friction and riding is a wholesome, fascinating sport of which a man should never tire until he seeks the chimney corner and an easy chair.

It is always advisable that the beginner should have a very steady horse which he will find that he improves with his own progress, and he will bring the horse up to his skill, but no further. A11 horses that are active enough for the saddle must have plenty of work or they may become too lively and skittish, and vices often result from the play of a fresh horse. A skillful rider can always keep his horse steady with the spur; but there is not one man in a thousand of those who ride who knows how to use the sharp rowel, or who has the patience to employ it with that delicacy and discretion that makes it the powerful instrument that it may become. 


\section{CHAPTER III. \\ THE SEAT OF A HORSEMAN.}

In these days we have but one form of saddle-tree, for sport or pleasure riding, and each man has in it his best seat possible; and there are so few differences in the proper positions that may be taken upon the flat saddle, due only to the conformation of individuals, that one may say that in all civilized countries men have the same seat. No longer do we hear of such absurdities as the "tongs across the wall," of the "long seat," or of the "short seat," for a rider can have but one seat that is the best for all purposes, and this he can find the first time he mounts a horse. It is silly for a man to think it necessary to have one seat for the park or road and one for cross country, for in the park or on the road the horse may make movements as violent as it would in the hunting field or in the steeple chase.

The writer has lived many years in various European countries and he has been a guest at the military academies of Saumur, Hanover and Vienna, besides visiting scores of riding schools in a number of cities, finding nowhere among real horsemen any observable changes in the position of the man upon the horse.

Baucher's description of the seat, written nearly three quarters of a century since, is the best and clearest that could be given: "Sitting upon the buttocks let the man take every possible point of contact with the saddle with the flat inner surfaces of his knee and the inside of his thighs; the feet finding themselves parallel with the sides of the horse without effort on the part of the man, and the length of stirrup leathers being adjusted so that the tread of the stirrups strikes the heels of the man."

A sure way in which one may find this seat is for the rider to mount the horse, and, sitting without rigidity, raise his legs so that the points of the knees meet above the pommel, then to drop the knees, very gradually, until their points and the flat inner surfaces of the thighs have every 
possible point of contact, the lower parts of the legs, from the knees downwards hanging loosely, until it is desired to in. sert the feet in the stirrup irons, when nothing more than the balls of the toes should feel the tread of the stirrups, and that in a light and elastic manner. Firmness of the seat depends upon the friction against the saddle and the suppleness of the man's body, particularly in the loins. If a man be not active he is safer and more comfortable in a motor car or in an xroplane, two abominations, than upon the back of a quick horse. But most men of a fair share of agility may learn to ride with pleasure and comfort at any age, provided they follow some good method.

Xenophon's description of the seat, the earliest represen. tations upon the monuments, the drawings of Fieschi about 1550, the portrait of Louis XIII, that of de la Guérinière by Parrocel in I 733, and that of Baucher in the first edition of his work, as well as the photographs of modern riders in this book, prove that the horseman's seat has been always and must have been always the same, except the absurd situations taken by men in armor who required peculiar saddles to maintain their positions on the horse, and whose seats, according to Froissart and other writers, were very insecure.

The seat must always be maintained, but the upper part of the body must conform to the movements of the horse, in obedience to the laws of nature for holding the position upon the saddle, and the lower parts of the legs, from the knees down, must be under perfect control, and are as of much use in the management of the horse as are the hands. That is, as should be apparent to every one, when the forehand of the horse rises, the body of the rider should be bent forward; where the hindquarters of the horse are raised and the forehand lowered, the body of the rider should be bent backwards, and the parts above the hips should bend with the horse as it turns, depending in amount upon the shortness and rapidity of the turns; in other words, the laws of gravity, of centrifugal and of centripetal forces must be observed as carefully in riding as in walking.

To excel in horsemanship one requires not only aptitude for the art, but agility, adroitness and readiness. Practice 
in dancing and in other callisthenic exercises are of great value in rendering the rider supple and strong; and there are many gymnastic feats which he may practice with good effect upon the horse standing in place, or moving; for example, leaning forward until one shoulder touches the crest of the horse; leaning back until his shoulders rest upon the croup; turning about in the saddle by passing one leg and then the other over the pommel and over the cantle; vaulting upon the horse and leaping to the ground while the animal rests, or is in motion, and other exercises that should suggest themselves. In vaulting upon the horse or in dismounting without stirrups, the left hand will seize a lock of the main half way between the withers and the ears, while the right hand, thumb under the pommel, will take hold of the saddle in a firm clasp. In leaping to the ground from a moving horse the man must be prepared to take some strides in the direction of the movement, maintaining control of the horse by the reins held in the right hand.

All of these exercises are very easy after a little practice, and they add quality to the rider's skill and confidence, while they render the horse quiet and accustomed to the sudden movements of the man. If when the trainer, in the beginning, finds the horse restless he should make the animal extend the forelegs occasionally, but always before mounting he should collect the horse by holding the reins under its chin and giving a tap or so of the whip upon the rump, so that the bearer should be properly under the mass before the man's weight is upon its back. The more frequently the horse is handled the more quickly it becomes steady, but no one exercise should be carried on to a point that will weary the horse, for young horses, at least, are easily bored and then become resentful. 


\section{CHAPTER IV.}

THE UNION AND BALANCE OF THE EXTREMITIES.

I remember reading somewhere of two "supernumeraries," of jealous dispositions, who spoiled the effect of a quadrupedal representation upon the stage by a want of coordination between the forelegs of the artificial animal and its hind legs. Some such result takes place when the young horse is mounted; for between the restraint of the hand and the urgency of the spurs or whip, not to mention the unaccustomed weight of the rider, the forehand and hindquarters are for a long time at variance. A young horse is awkward enough without any interferences, but when the man mounts it must be given a proper carriage in order that it may move smoothly and evenly in cadenced motions. When a horse becomes safe and pleasant to ride it is always the result of a series of experiments upon the part of the rider or because it has been scientifically handled by a trainer who had a good method. In the first case one could never have perfection, but a thorough horseman can make the animal he trains a machine that answers every demand, on the moment and precisely.

To obtain this coördination of the extremities a few lessons on foot are of great use, although a horse may be trained from the saddle or, as I have intimated, without having been mounted. The normal and usual process, how. ever, is the following:

The essential thing is that the horse is to go forward. Even when the animal is made to back it must be induced to take a stride, or at least an inclination, forward before it is permitted to come to a rest. So the young horse is first ridden in the snaffle and made "to go into the bridle;" that is, to move forward freely against a tension upon the reins.

The horse having been brought "quiet to ride" in the snaffle is ready for the higher education; and, as has been said, more rapid advancement can be made by a few lessons with the man on foot than by his riding the animal as soon 
as the double-reined bridle is employed; for no horse can be trained without bit and bridoon, unless it be in the snaffle alone in the hands of an exceptional horseman, when much reliance must be placed upon the assistance of the spurs in its control.

The following exercises are called the suppling lessons, and by them we overcome all resistances of the horse, whether active (intentional) or passive (due to conformation), so that the horse is pliant and obedient throughout.

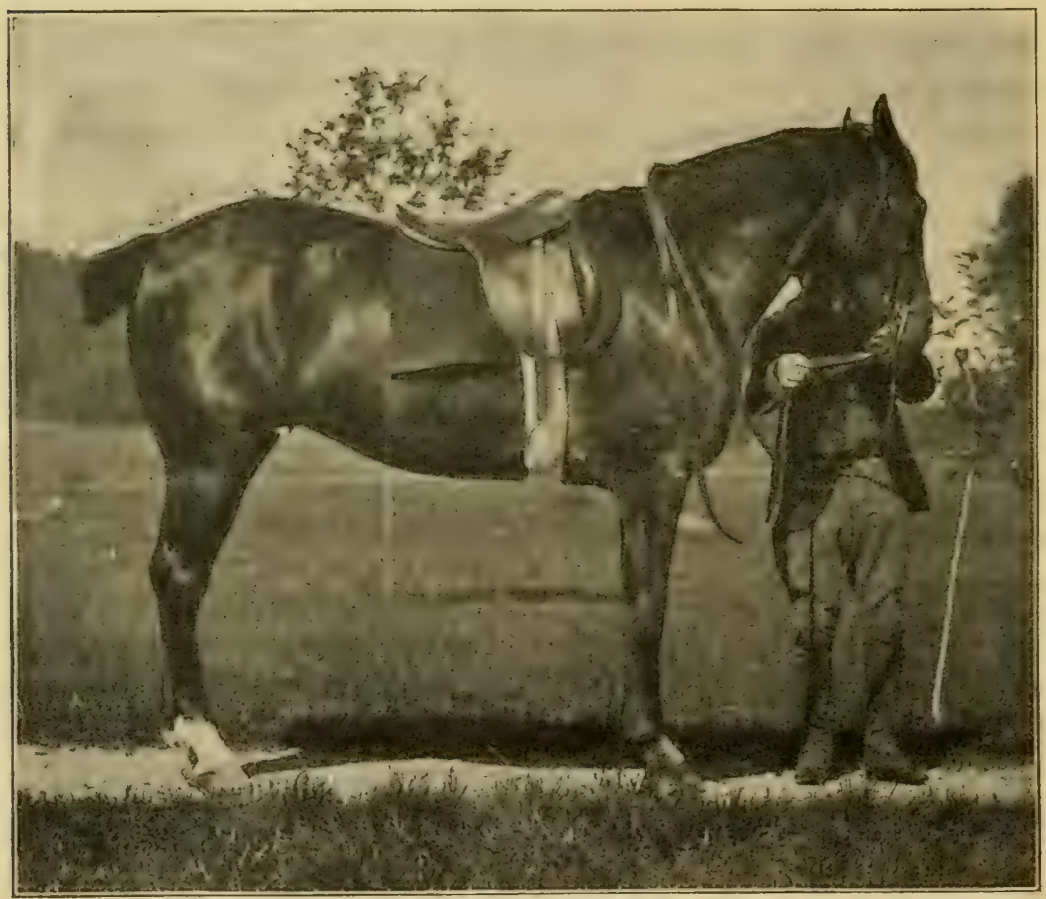

Direct Flexion of JAw AND Pold. (Anglo-Normand).

Photograph by M. F. A.

The first work is upon the forehand, or those parts of the horse before the saddle. The trainer standing in front of the horse should take a snaffle rein in each hand and elevate the head to the full extent of his arms, and then gradually and gently bring it back to such a height that seems to him the natural carriage of the head, demanding, without 
violence, that the face should be about vertical to the plane of position. Then standing on either side of the horse near its shoulder, he should draw the snaffle reins away from the nose of the horse with one hand while with the other he should by gentle vibrations draw the curb reins, held under its chin, towards its chest, yielding the snaffle reins as the animal gives its jaw and drops its nose until the face is about vertical. When the horse curls the upper lip and has a perfectly pliant, but not lifeless, feeling upon the reins

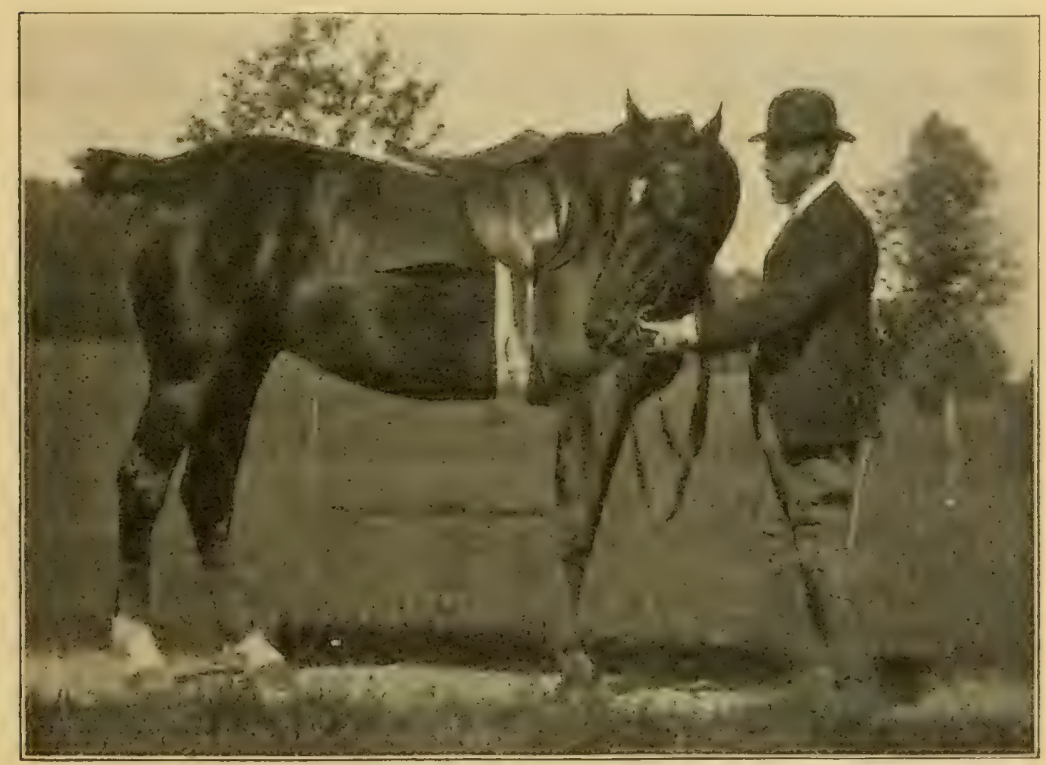

Bending Head and NeOK With CURB Bit.

Photograph by M. F.A.

the objects of these two lessons have been accomplished. In these exercises the face of the horse should not be drawn nearer to the chest than the vertical position mentioned, and the head should rather be higher than the natural carriage than otherwise. Regarding the next exercise I feel bound to say that it has aroused much opposition from those riders and trainers who think that the horse should be kept straight under all circumstances; but as I have found it so valuable in many ways and required for so many important movements, 
and as I have the support of horsemen of the first force, I do not hesitate to recommend it as absolutely necessary. Standing at the head of the horse, on its right side, the man should grasp the reins of the curb bit near the branches and turn the bit by pushing with the right hand, while drawing the left hand towards him; in this manner he should gently and quietly bend the head of the horse to the left, and then by an equal, vibratory tension upon both reins procure the pliancy of the jaw and of the neck, as before described. In a similar way, the man standing on the left side of the horse should bend its head to the right. After it has been bent sufficiently to satisfy the trainer, the head of the horse should be placed straight, and the direct flection of the jaw be demanded, and the horse should be encouraged in its obedience. At no time during these lessons should the horse be permitted to draw back without being brought to its original position and corrected by the voice, or be made to advance by a gentle tap of the whip upon the chest. It might be as well to mention here that, at this stage of its education, the horse should never be given punishment with the whip, or be struck on the hind legs. There are times when a sharp blow of the whip has a very good effect, say, when a horse pretends to shy, or gives a kick at whip or spur, but by a second application or by further strokes only mischief will follow, and the whip, instead of being an "aid," becomes a danger, for the horse is a determined fighter and will seldom "give in."

Two very simple exercises, with the trainer on foot, prepare the way for obtaining control of the hind quarters, or those parts of the horse behind the saddle. I. Let the man stand on either side of the head of the horse and with the snaffle reins held under its chin keep the animal in place, as he gives some gentle taps of the whip upon the croup, so that the horse will carry the hind legs under the body. After one or two lessons the whip taps should be applied to one or the other hip, so that the horse will carry forward the right or the left hind leg as may be desirable. 2. To carry the croup about the forehand, let the man stand at the left shoulder of the horse, and in the left hand hold the snaffle 
reins under the chin of the animal; then with the right hand let him give one tap, or more, of the whip to the left flank until one step is taken to the right. Gradually, step by step, the croup will be carried about the forehand, the left foreleg acting as pivot, the right foreleg being moved to conform to the movement by whip taps upon its under side. In a similar manner the horse should be made, by gradual lessons, to

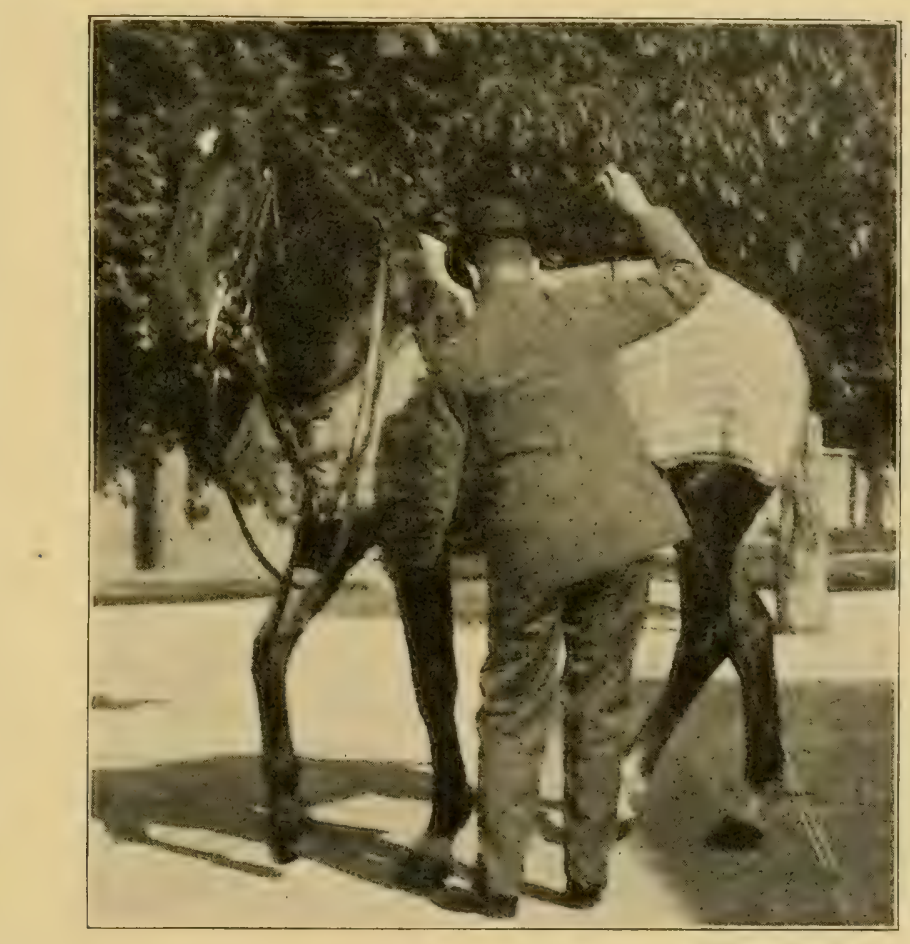

Croup about Forehand. Left foreleg the Pivot. Photograph by Dorothy Woods.

carry the croup to the left, around the right foreleg as pivot, the man standing on the right side of the horse, demanding each step singly and refusing to accept a voluntary movement.

During the period of these lessons which should occupy about half an hour each day, the horse should be exercised sufficiently upon the longe line, and by being ridden at the 
walk and slow trot in the snaffle bridle. In the latter case the horse should be accustomed to the pressure of the rider's heels, by being collected for the changes of direction upon a closing of the rider's legs, and, at the turn, being made to conform to the arc of the circumference by an increased pressure of the outside heel; the direct rein, supported and its effects measured by the outside rein, demanding the turn, an equal tension upon the reins following its completion.

When the suppling exercises have resulted in a pliancy of the muscles and in a ready obedience to the whip taps the horse is to be ridden in the dotible-reined bridle, and by governing the extremities, between heels and hand, the rider will gradually produce the desired condition of union and balance of the weights and forces, and so be master of any movement-forwards, to the rear or to either hand-that he may wish.

When there is a perfect state of union and balance of the forces there can be no motion, and changes of position are made by one extremity yielding sufficiently to produce the effect sought. In violent actions the center of gravity is changed with a corresponding violence, as in the rapid paces or in leaping, rearing or plunging. But the schooled horse is instinctively obedient to the rider, and only those movements take place that he demands. Not only can the rider require from the trained horse of good conformation every possible movement, but faults of conformation may be corrected by an artificial carriage so that nearly every horse may be brought to move in easy, smooth and cadenced paces and motions. Indeed it may be stated that any horse with four good legs can be made safe and pleasant to ride, while the ideally formed horse must ever be awkward under a rider until it is given an artificial carriage. 
CHAPTER V.

THE SPUR - IN HAND-CLOSELY UNITED - THE HALF HALTTHE REINS.

Ordinarily the spur is a hindrance rather than an aid. A horse either shrinks from the sharp rowel or breaks away unless, as sometimes happens, it becomes a sluggard and has to be kicked along to keep it going Properly employed the spur is an important, and in some cases is more important, than the bit; for examp.e, in stopping a "bolt"; but in any event it is indispensable in the management of a horse, and in the use of a true horseman gives at the outset no more than a scratch, for after a few brief lessons the application of the sharp rowel is no longer required, as the side of the rider's heel or the pressure of his leg will be all that is necessary. The most nervous horse can readily be taught to bear and to obey the sharp spur with composure; and such a state of affairs gives an assurance of safety to the rider in many ways, for the horse will neither rush off upon an accidental scratch nor refuse to obey his demands. No one can give the proper application of the spur whose seat is not perfect, for no matter how violent the changes of the center of gravity may be the rowel should be used with such precision that, at most, only a scratch is made. But the trained horse would on occasion take and obey a severe use of the aid without resentment. During the early lessons under the saddle the horse should be taught to obey the heel of the rider, a tap of the whip upon the flank sometimes being required to enforce the pressure of the heel. After the horse has been accustomed to this form of the "leg aid" dull spurs may be used for a while. Then the horse should be ready to accept the sharp rowel, and upon the occasion of a lesson the rider should give a slight scratch upon one flank with the points and calm the horse by soothing words or by strokes of the hand. After an interval the other flank should receive a similar attack and the horse be quieted in the same manner. After a few such lessons the horse will not require the 
sharp rowel, and the dulled spur or the side of the rider's heel will be obeyed with alacrity and precision.

The horses employed for the photographs in this work were ridden in spurs that had no sharp rowels, and I may say that blood had never been drawn from them by the spur.

The forehand of the horse being under the control of the rider, and the hindquarters being under the control of his heels, the man may readily demand such a union and balance of the extremities as he desires. A rule that must always be observed is that the effects of the heels should always precede those of the hand, for the hand must always have impulses from the croup to direct and manage.

The lowest form of collection in which lies safety and comfort is that which is known as "in hand," that is, when the motions of the horse are at least obedient to the rider's will.

If one mounts a horse, whose education has been carried as has been described, and quietly closes his legs against its sides before making a few vibrations of the reins, the horse will bring its bearers under the mass, drop its nose, yield the jaw, and show by the play of muscles under the rider that it is alert and ready to move off "in hand." A gentle yielding of the hand permits the horse to proceed in a walk, and then between heels and hand the rider should keep the weights and forces in the condition explained. Should the horse bear upon the hand and go too much upon its shoulders it should have the hind legs brought up under the body and the head slightly elevated. The horse should be ridden "in hand" at the walk, the trot and the slow gallops; the heels of the rider demanding sufficient impulses from the hindquarters, his hand directing and controlling these impulses, while between the heels and hand the proper balance and suppleness should be demanded.

A closer form of collection may be required and the increased impulses will go into increased action, when we shall have the shortened trot, the passage, or the school gallop of four beats. When the extremities are brought to a state of equilibrium, there can be no progress, and we shall have the 
half-halt, the finished halt, or, if action is demanded, the dancing steps known as "the piaff."

The half-halt can be held but a moment, while the horse is light and one leg at least is flexed. When all the feet are on the ground the horse has lost its lightness and the halt is complete.

When the horse is brought to a halt, the rider's legs

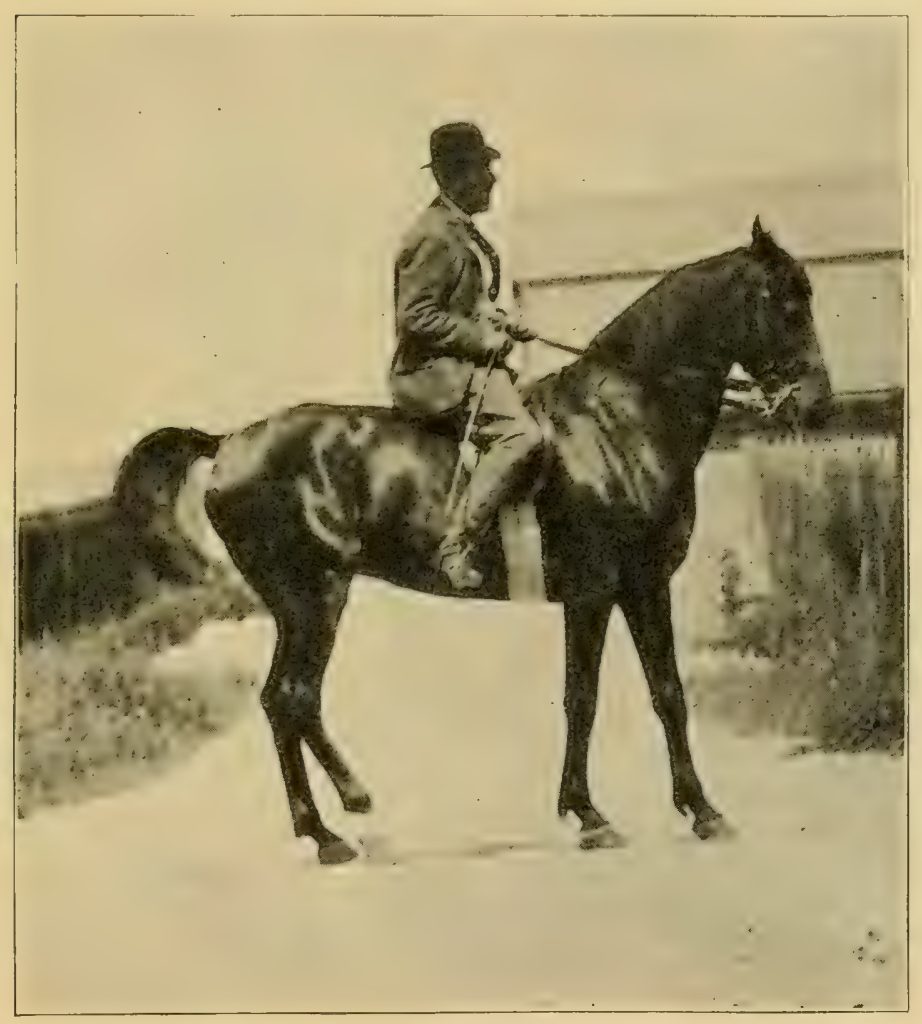

Hatf halt. The Horse is Prepared to go Forward or to the Rear.

Photograph by Dorothy Woods.

should not be withdrawn until the tension upon the reins has ceased.

There are a number of ways in which the reins of the double-bridle may be held. In riding a young or a difficult horse, I hold in the left hand the left curb rein between the 
little finger and the ring finger, the left snaffle rein between the ring finger and the long finger, thumb uppermost; in the right hand, knuckles upwards, I hold the two right reins divided by the forefinger, the snaffle rein next to the thumb. In this way one has great control over the mouth of the horse by the direct reins, and the right reins can easily be shifted into the left hand.

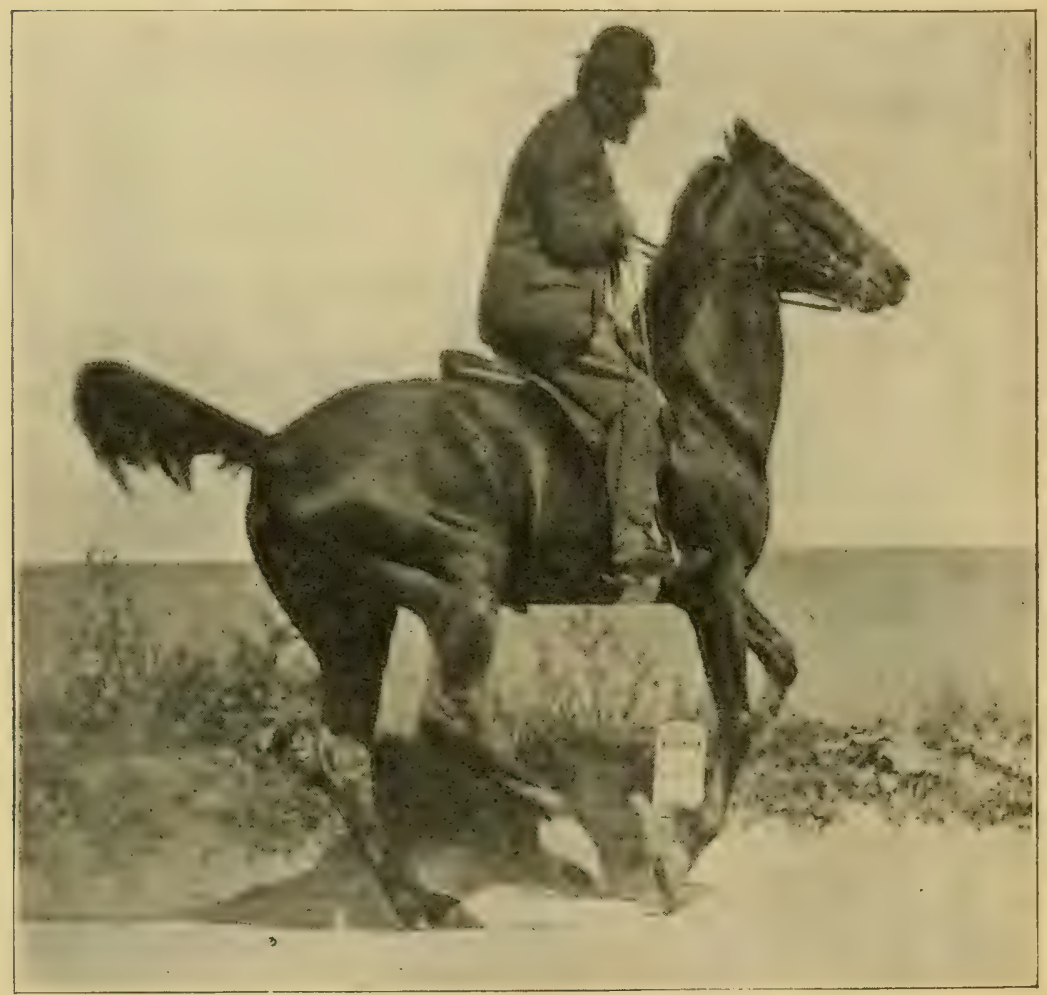

UNITED OR SOHOOL GALLOP OF FOUR BEATS.

Photograph by Dorothy Woods.

In riding a schooled horse I carry all the reins in the left hand; the curb reins divided by the little finger, the snaffle reins divided by the long finger, the loose ends carried through the hand and held by the thumb which is uppermost and pointing between the ears of the horse. The right 
hand lying on the ends of the reins, when not otherwise in use, and ready to assist the bridle hand.

There should not be a tension upon both sets of reins at the same time; that is, when the snaffle reins are in use the curb reins have no tension, and the snaffle reins are loose when the curb reins are in action. In riding with the left hand alone the turn to the left should be made by turning the thumb over the left shoulder of the horse and then by carrying the reins to the left. In turning to the right, the thumb should point towards the right shoulder of the rider and then the reins should be carried to the right. By this mode the danger of giving a wrong indication is avoided, and in demanding the gallop and the gallop turns and changes the direct rein controls the movements from the beginning, and there can be no confusion in the demands of the rider. When the right hand is free it should assist so that the direct rein acts in changes of direction, in beginning the gallop, and in the gallop turns and changes, because it is well to keep the horse accustomed to obeying the direct rein, and because the other rein can in this way better measure and control the effects of the direct rein.

In reducing speed and in coming to a stop the rider should increase the pressure of his heels and slightly raise his bridle hand and it must be borne in mind that the horse should always be brought to a finished halt by the action of heels followed by that of the hand, the tension upon the reins being loosened before the heels are withdrawn. 


\section{CHAP'TER VI.}

\section{MUVEMENTS TO THE REAR.}

A horse fit for riding should back freely and smoothly. The first lesson, and a very important one it is, should be given while the trainer is on foot. Placing the horse alongside of a wall the man should hold the snaffle reins under the chin of the horse with one hand and with the other hand give a few taps with the whip upon the rump to unite somewhat the extremities. Then by a repeated tap of the whip upon the rump, the trainer should produce an impulse and carry the flexed leg to the rear one step, immediately inducing a forward movement. Gradually, very gradually, the horse should be taught to take several steps to the rear always being induced to go forward before coming to halt. In other words, at the point where the backing ceases and the forward movement begins there should be no decided halt, but the body of the animal should drift like a pendulum, backwards and forwards, and then the stop.

After a few such lessons the rider should mount, and after bringing the horse in hand, between heels and rein, he should increase the pressure of his legs until he feels an impulse when he should release his heels and carry back the flexed leg one step, then stop the movement by his heels and demand a step or two forward and finally a halt. As gradually as the rider's patience will permit, and a horseman should be fitted out with unceasing patience, the steps to the rear should be increased until the horse will move in a balanced and cadenced movement as far as may be desired; at least one step forward always being required before a halt.

Before many days the horse may be made to pass to the rear without any touch upon the reins, by the use of the spurs and the position of the body of the rider.

In backing, the turns and changes of direction may be made with the same precision as in the forward movements, the croup being turned to the left by the right spur and the right rein, measured and controlled by the left spur and the 
left rein; and the croup is turned to the right by an interchange of spurs and reins.

I have often been asked by beginners how it is that the spur demands the forward movement, the halt, and the passing to the rear; all of which can be procured without the employment of the reins after a little practice.

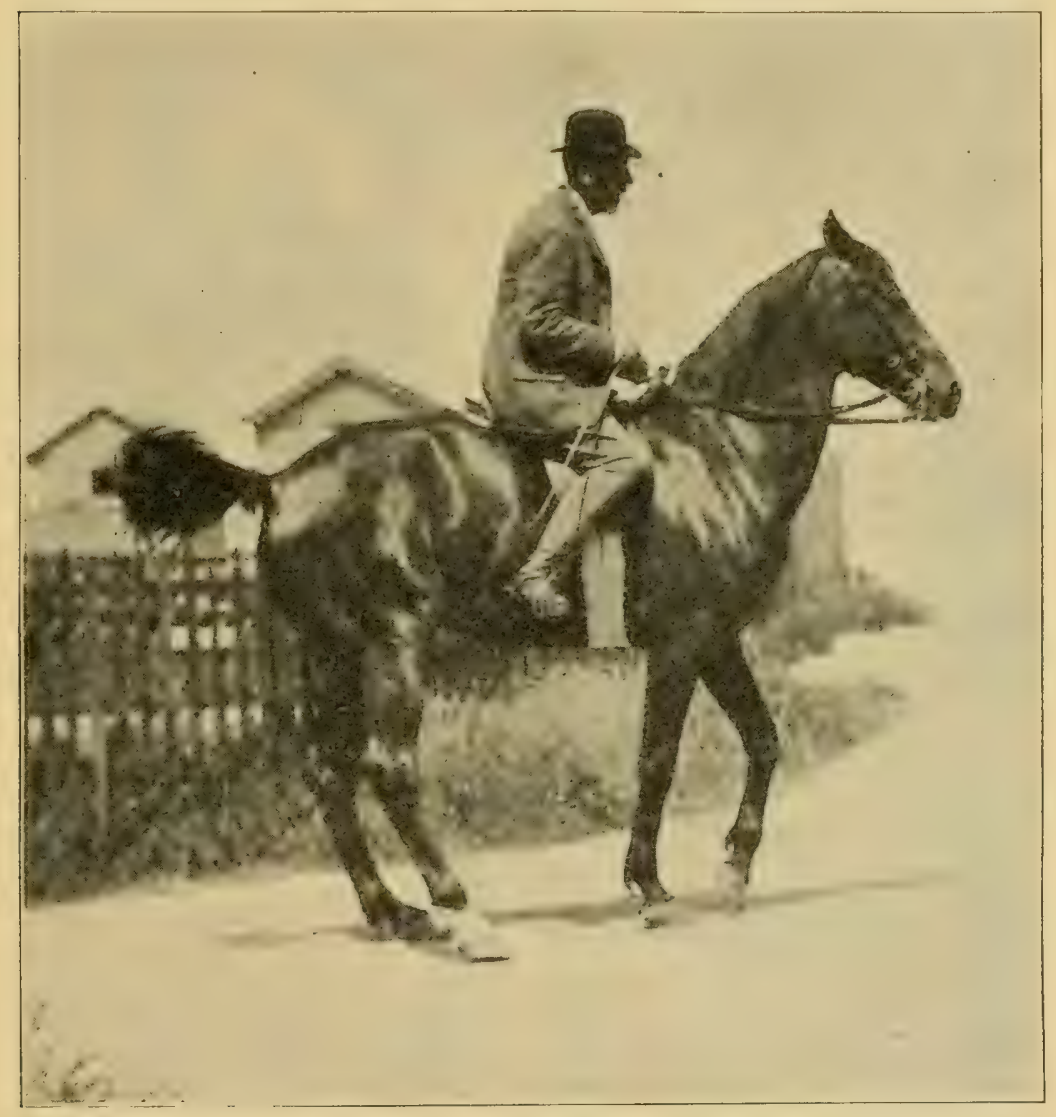

BACKING WITH THF SPURS.

Photograph by Dorothy Woods.

This question may be answered by the statement that the spur requires impulses from the croup which first carry the hind legs under the mass. If the hand gives permission the horse moves forward under the impulses; if the forehand is 
raised and the body of the rider is thrown back the hind legs come under the body and act as an elastic break or drag; if the impulse be caught and turned back before the movement forward is made the horse goes lightly to the rear.

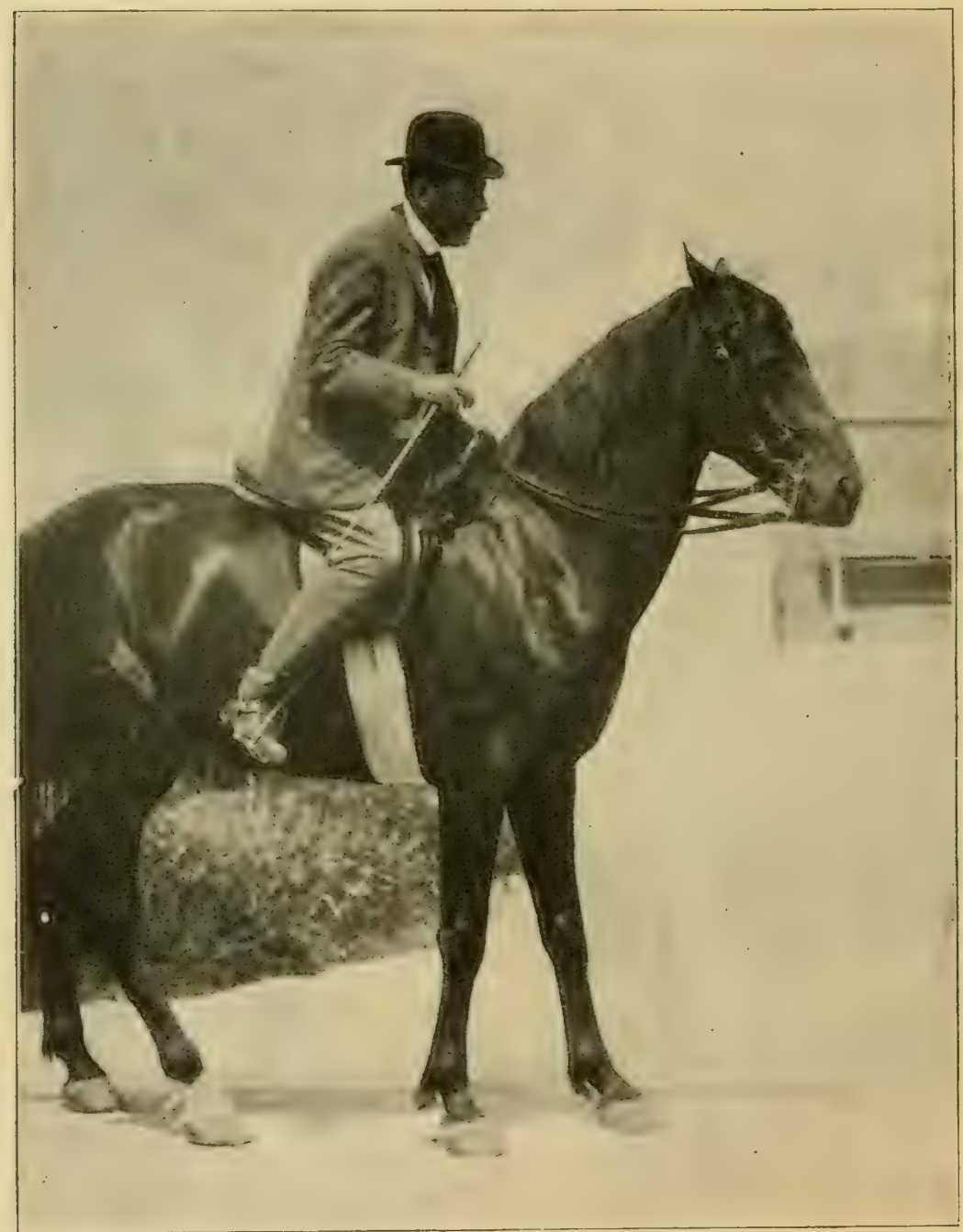

BACKING WITI SPURS, WITHOUT TENSION UPON REINS. Photograph by Mary Woods.

Now after this explanation it should be understood that during the lessons in which the reins are employed the horse, 
which is a very observant animal, learns how the rider uses his body in the various movements and will be ready to obey the spurs, nor does it always require the action of the reins which never precede that of the heels.

It now occurs to me to explain the difference between a step and a stride. A stride is the ground covered by the mass from the moment any certain foot leaves the earth until it is again planted; example: in gallop right a stride is from the time the right hind leg drives the mass over the right foreleg into air until the same hind leg again comes to the ground. A step is the raising and next planting of any leg; for example: in beginning to move the croup about the forehand the horse may take one step with one of the hind legs, the other legs holding the ground. 


\section{CHAPTER VII.}

ON TWO PATHS - FOREHAND ON OUTER CIRCUMFERENCE OR TRAVERS - CROUP ON OUTER CIRCUMFERENCE OR RENVERS - PIROUETTE-REVERSED PIROUETTE.

Travers and Renvers are the movements upon two paths, the forehand following one path; the croup, slightly behind in the movement, following the other path, in such a manner that the horse is placed diagonally across the line of progress. When at the turns and changes of direction the forehand is on the outer arc of the circles we have the Travers. When the croup is on the outer arc of the circles in the turns we have the Renvers.

When in Travers the turn is so short that the inner hind leg of the horse acts as pivot, we have the Pirouette, or, if in the beat of the gallop, the Pirouette-volte.

When in the Renvers the turn is so short that the outside foreleg of the horse acts as pivot, we have the Reversed Piroutette.

In the lessons on Croup about Forehand, with the whip, we have prepared the horse to yield the croup at the pres. sure of the rider's heel, and these effects will now be em. ployed for all the movements on two paths, whether Travers, Renvers, Pirouette or Reversed Pirouette.

The readiest way in which to begin the work upon two paths is to place the head of the horse near a wall, the forehand slightly in advance of the croup as regards the lines of progress, let us say to the right. The rider should then lead the animal along to the right, while with his left heel, its effect measured and controlled by the right heel, should press the hindquarters along as the body of the horse holds its diagonal position across the lines of progress.

In making the turn to the right, the croup on the inner shorter arc of a circumference should be slightly retarded so that at every point of the body of the horse shall hold its diagonal position. In head to the wall to the left the forehand 
in advance of the croup, should, in a similar manner, be led on to the left by the reins, the hindquarters being pushed by the rider's right heel, its effect measured and controlled by his left heel. At the turns to the left the forehand being on the outer greater arcs of the circumference, the croup will be retarded, as in passing to the right. The effects of the

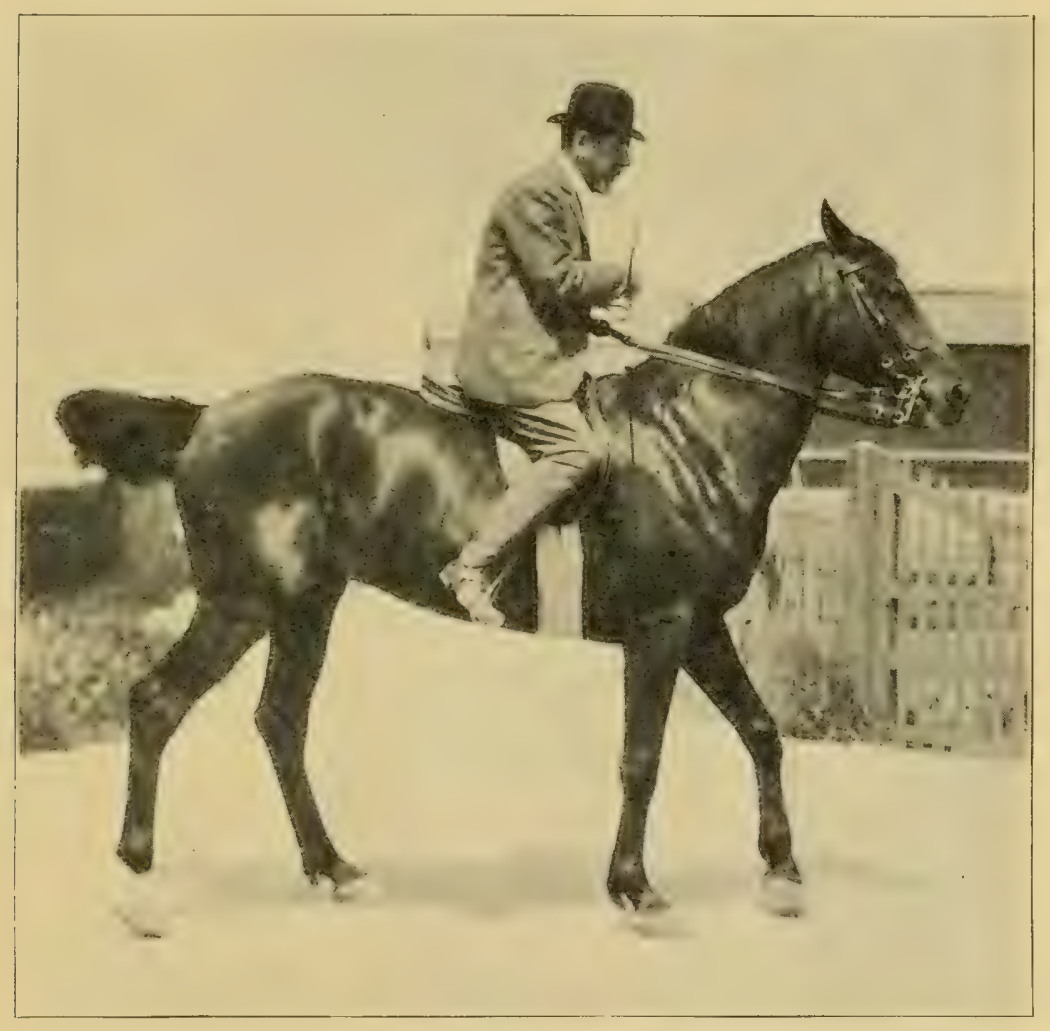

DRIFING, FORWALD AND BAOK. BAEANOE BETWEEN SPUR AND REIN. Photograph by Mary Woods.

rider's heels in these movements may be supported in the early lessons by light taps of the whip, and to apply the whip to the left flank of the horse the man may carry it behind his back, or he may shift the reins to his right hand and take the whip in his left. But as soon as the horse begins to un- 
derstand the heel pressure the use of the whip should be discontinued.

Croup to the wall, or Travers to either hand, is done in exactly the same manner, the forehand slightly in advance of the hindquarters, but in Travers, as the hindquarters are on the outside larger arc or circle, at the turns, the forehand

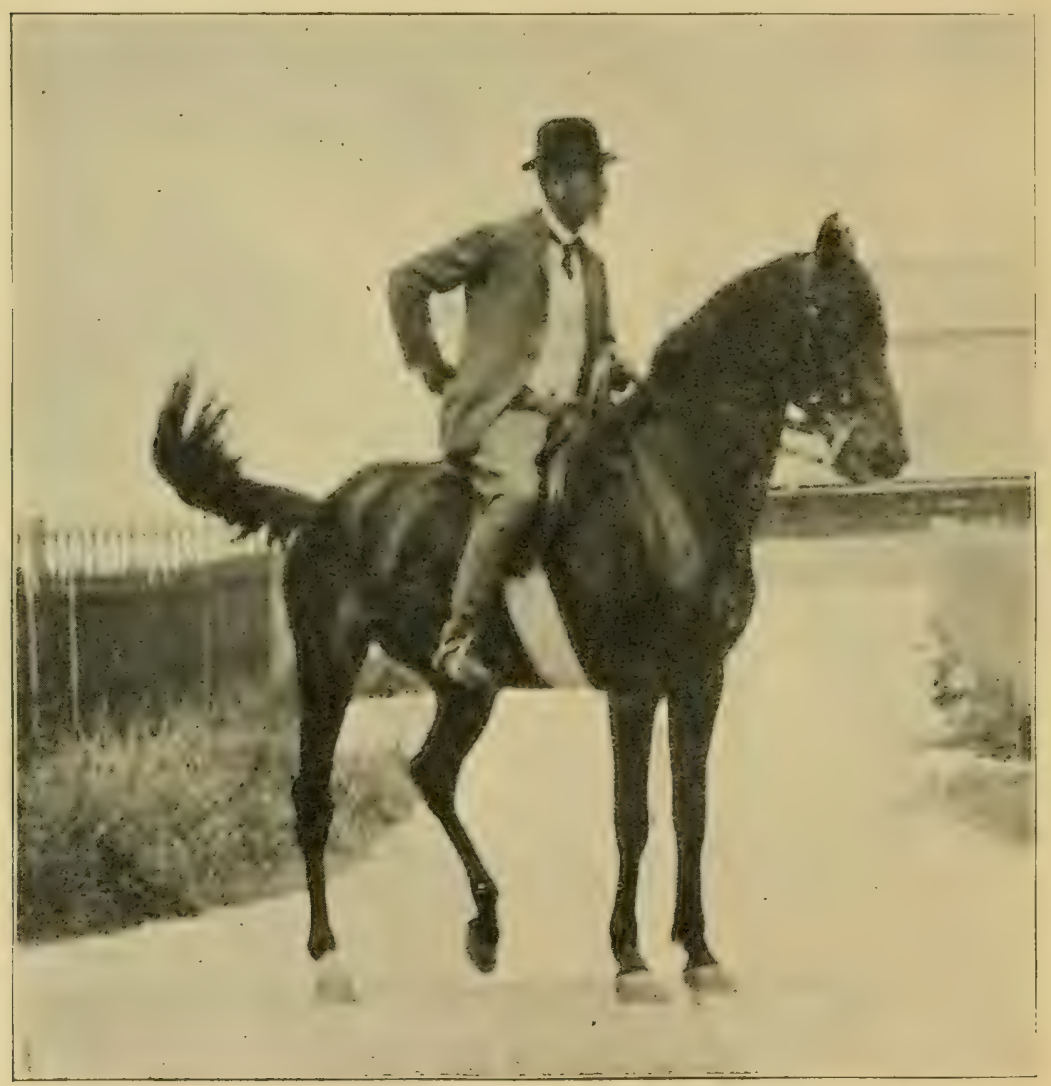

Use of Whip in Brinding Choup ABodt Forkhand to the Right. Photograph by Dorothy Woods

must be so retarded that the diagonal position of the body of the horse shall be preserved at every point on the turns or circles.

These lessons should be practiced at the walk until the horse is quite perfect in both Travers and Renvers in that 
pace, then it should be made to pass in two paths in the trot and finally in the shortened gallop.

As has been said when the turns, in the walk, in the trot or in the gallop, are so abrupt that in Travers the inner hind leg acts as pivot we have the Pirouette. When the turns

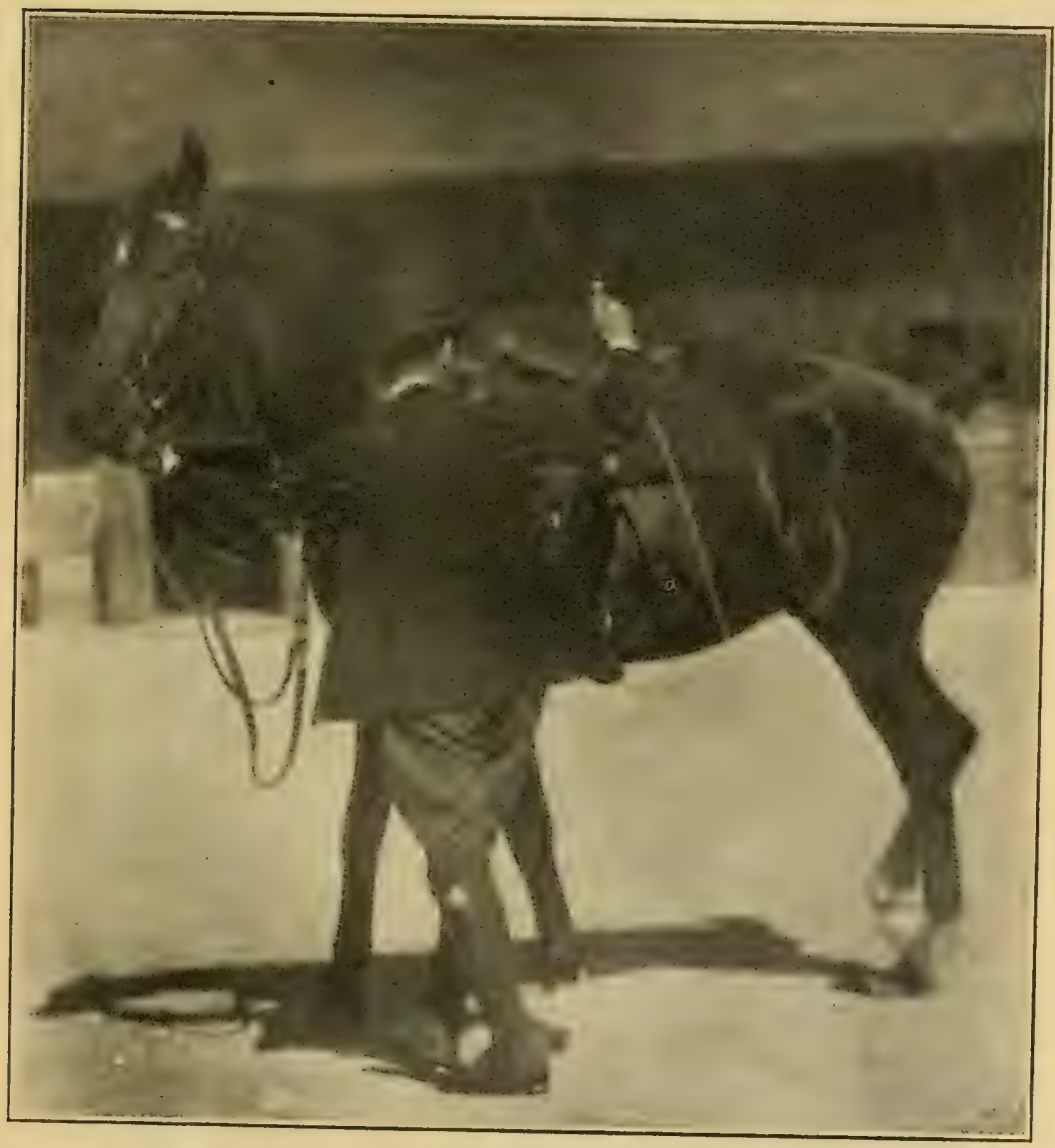

USE OF THE WHIP IN TRAVERS. (ANGLO-NORMAND).

Photograph by the Author.

in Renvers are so abrupt that the outer foreleg acts as a pivot we shall have the Reversed Piroutte; that is, when the croup passes to the right about the left fore leg as a point we shall have the Reversed Pirouette to the right. In a similar manner, when the croup passes about the forehand to the left so 
that the right foreleg acts as pivot "we shall have the Reversed Pirouette to the left.

In all work in Travers and in Renvers the head of the horse should be slightly bent in the direction of progress; so

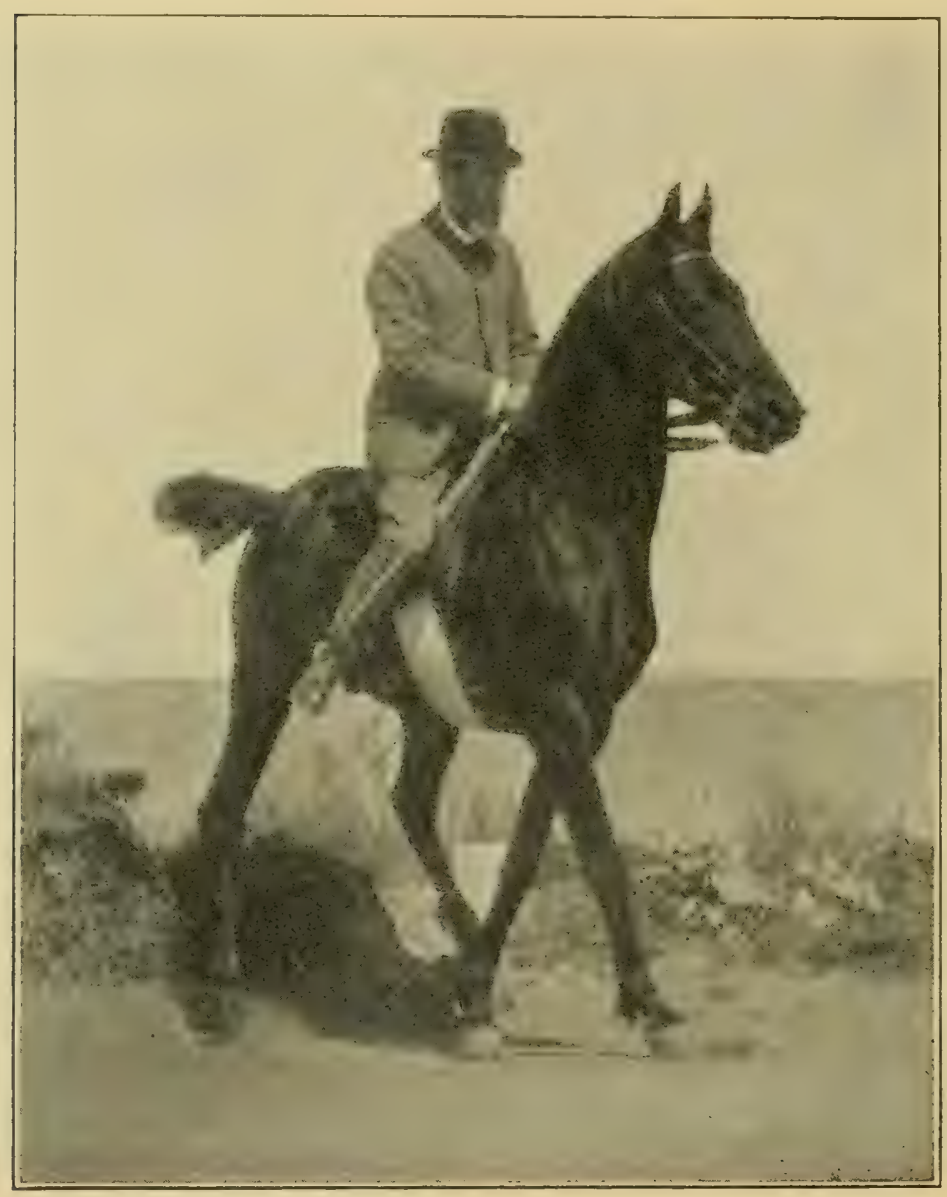

RENVERS, ON TWO PATIS TO THE LEFT.

Photograph by Dorothy Woods.

that in the Reversed Pirouette the horse should look towards the croup as it goes about the forehand.

All of these movements upon two paths, including the pirouettes, are of the highest importance to all of those who 
are to be considered as horsemen, and to mounted soldiers they are absolutely essential, for the trooper who has the

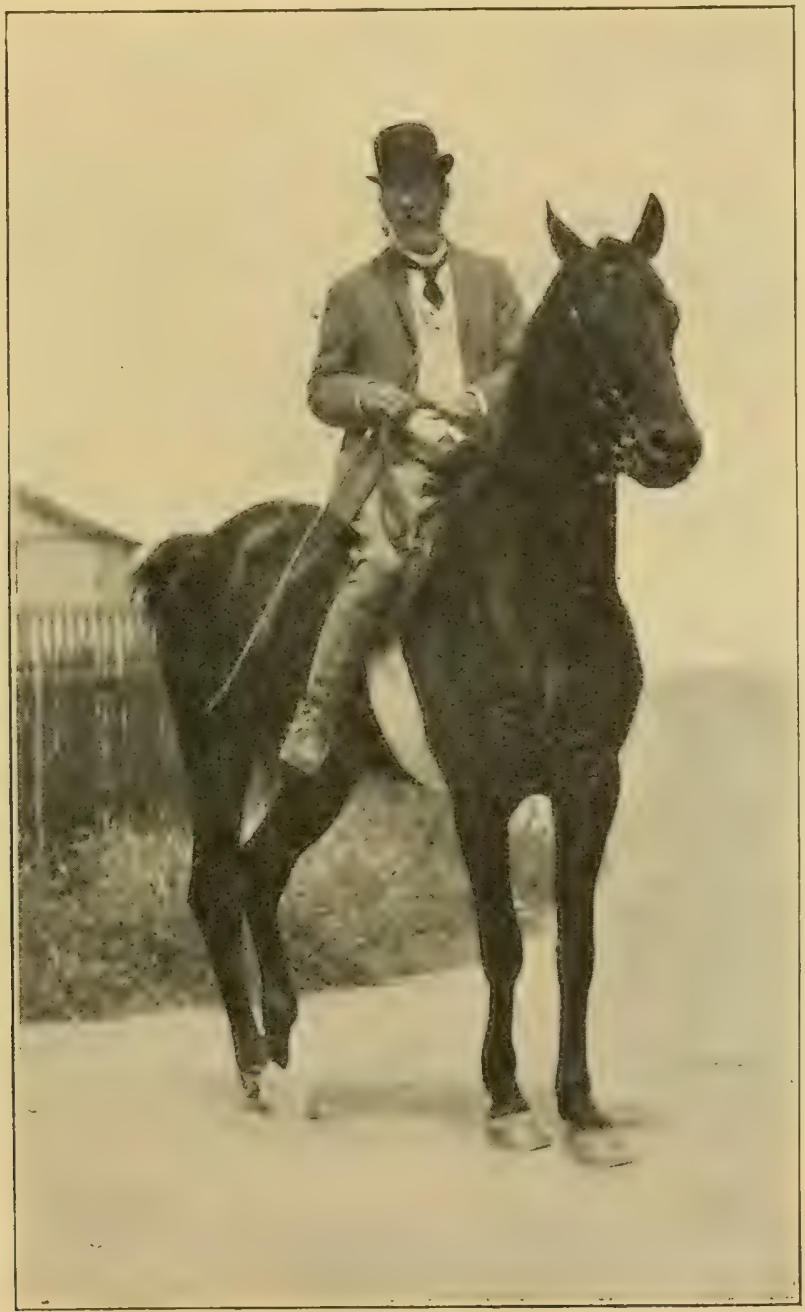

Pirouette. Right Hind Leg tire Pivot.

Photograph by Dorothy Woods.

readiest horse in turns and wheels has his opponent in his hands. 
To those who argue that the bending lessons are not only useless but harmful, I can only say that I have found that the more supple and pliant I can make my horses the more readily I can keep them straight when it is required; and the precision with which all the movements were made,

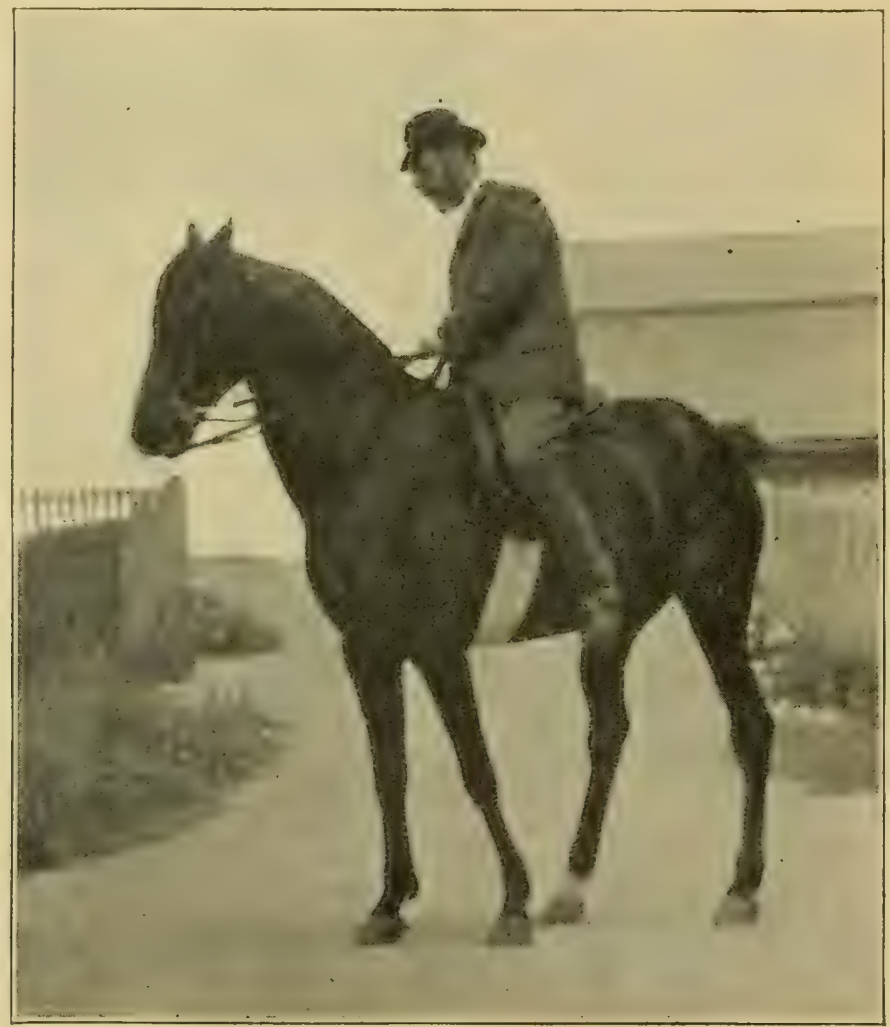

Reversed Pirouette. Left Foreleg the Pivot.

Photograph by Dorothy Woods.

whether straight or bent, is proved by the scores of moment photographs of half a score of horses, printed in "Modern Horsemanship," in " Riding," in "The Cavalry of To-morrow," in this book, and in my various magazine articles, for in each picture the position is exactly right. 
CHAPTER VIII.

THE GALLOP. THE GALLOP CHANGE. THE IIALT IN THE GALLOP.

In the gallop the horse, in each stride, goes into air from a fore foot; the opposite hind leg is then planted, then the fore leg diagonally opposed to the last named, and finally the first fore leg from which it goes into air for another stride.

The horse is said to lead with the fore leg from which it leaves the ground, and that leg and the hind leg of the same side are planted in front of the other fore leg and the other hind leg respectively. That is when the horse is leading with the right fore leg, it is said to be in gallop right, and that leg and the right hind leg are planted in front of the left fore leg and of the left hind leg. In gallop left, the horse goes into air from the left fore leg, and the legs of that side precede, in each stride, the legs of the right side.

In turning in the gallop to either hand, the horse should lead with the side to which it turns so that a bearer will always be under the center of gravity or ready to receive the weight. If in turning to the left, the horse be in gallop right, the animal may fall as the outside legs will be the ad. vanced ones, and there will be no bearer quite under the center of gravity at a critical moment.

When the second hind leg and its diagonally disposed fore leg come to the ground so nearly together as to make one sound we have the ordinary gallop of three beats.

When in extended form the racing horse plants one leg after another like a spoke of a wheel, we have an example of the gallop of four beats; and when in the shortened gallop the horse is so closely united, and its body so supported that the hind leg which is planted second comes to the ground before the diagonally disposed fore leg, we have another example of the gallop of four beats. 
The horse should not be made to gallop until it has been taught to move in the various forms of collection in the walk and in the trot; otherwise it will be difficult to procure a cadenced gallop in such conditions of the union of forces as are desirable.

To put the horse into right gallop, from the halt, the walk or the trot, the rider should unite the extremities somewhat and increase the pressure of the left heel while giving an upward play with the right rein; the other heel and the other rein measuring and controlling the acting

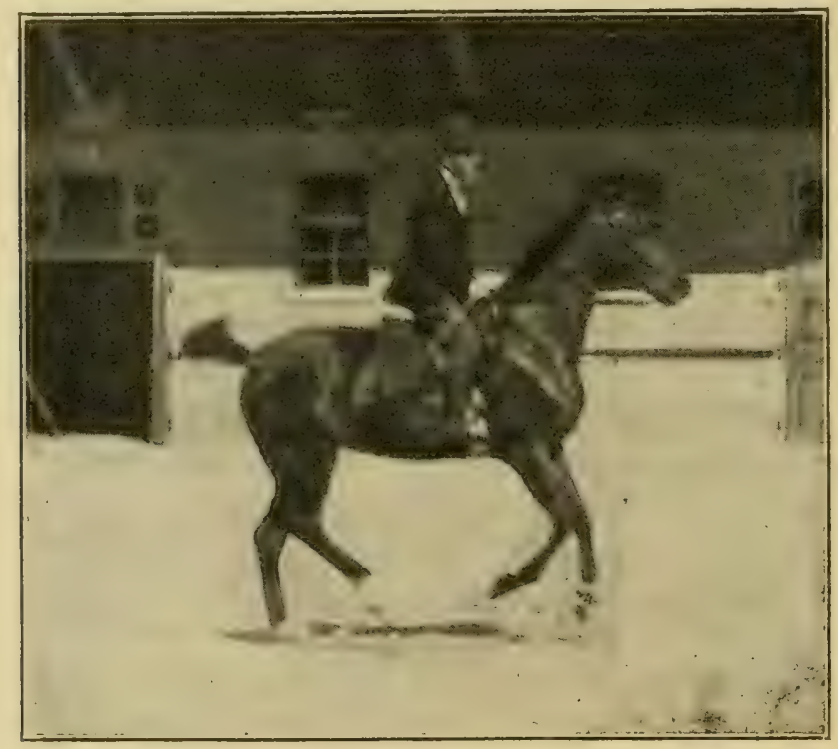

GALLOP RIGHT.

Anglo Normand, trained and ridden by the Author.

heel and rein so that the horse will go into the gallop as straight as may be. Once the gallop is taken the rider will maintain the impulses with the heels and control them with the reins so that the pace shall be even regular and cadenced.

The gallop left should be demanded by the right spur and the left rein, controlled and measured by the other spur and right rein. When a horse turns to the right (or left) in gallop left (or right) it is false. When one extremity has 
galloped right (or left) and the other extremity gallop left (or right) it has the cross gallop, which is wrong.

For some time until it is confirmed in obedience, the horse should be ridden in the gallop in the state known as in hand, afterwards the collection should be closer until the shortened gallop, the half-halt, and the halt in the gallop may be demanded. Finally the rider may extend the horse in as rapid a pace as he disires, bringing it gradually to a controlled pace before he comes to a halt.

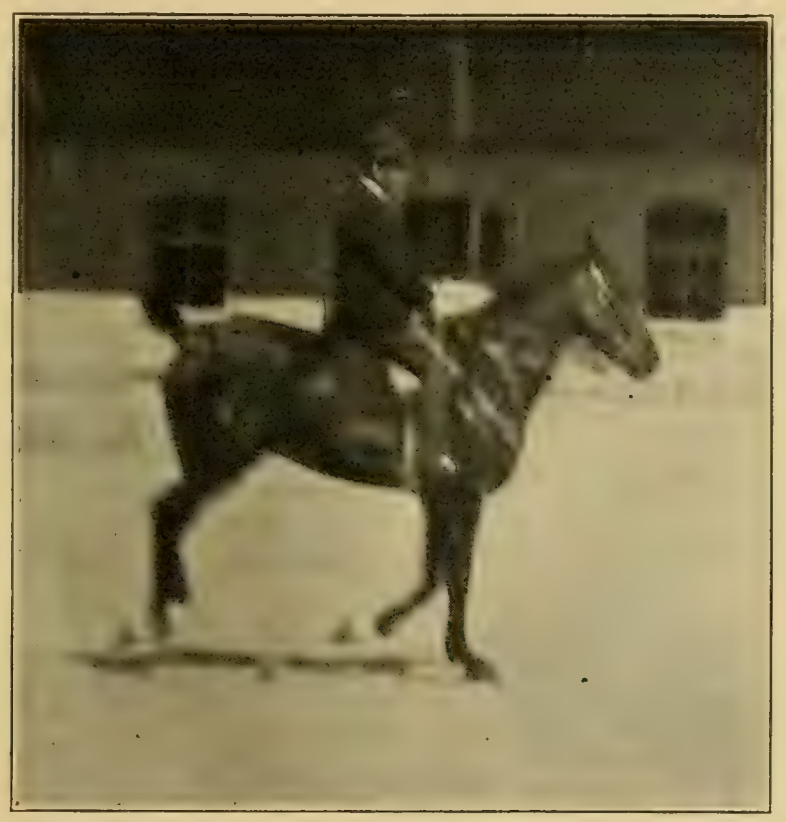

GıLJOP RIGHT.

Photograph by Dorothy Woods.

It should always be borne in mind, that, unless some unexpected occasion rises, the speeds should be gradually reduced by the action of the heels and hand, and the halt be made from the walk. But the halt may be made in any stride of the gallop, by the rider closing his heels and raising the bridle hand, without danger of injury to the horse; for the flexed hind legs are carried under the mass in such a manner that there is no jar. I have been riding trained 
horses for more than half a century, and I have never had a horse throw a spavin, and my horses last well; one was perfect for fifteen years. Indeed the work of bending keeps them supple and active long after the age that horses usually become useless for the saddle.

The horse should be ridden in the gallop upon straight lines, in changes of direction to either hand, upon two paths, reducing the circles of Travers until the pirouette in the beat of the gallop results, and in figures of eight.

Most of these movements may require the changes of

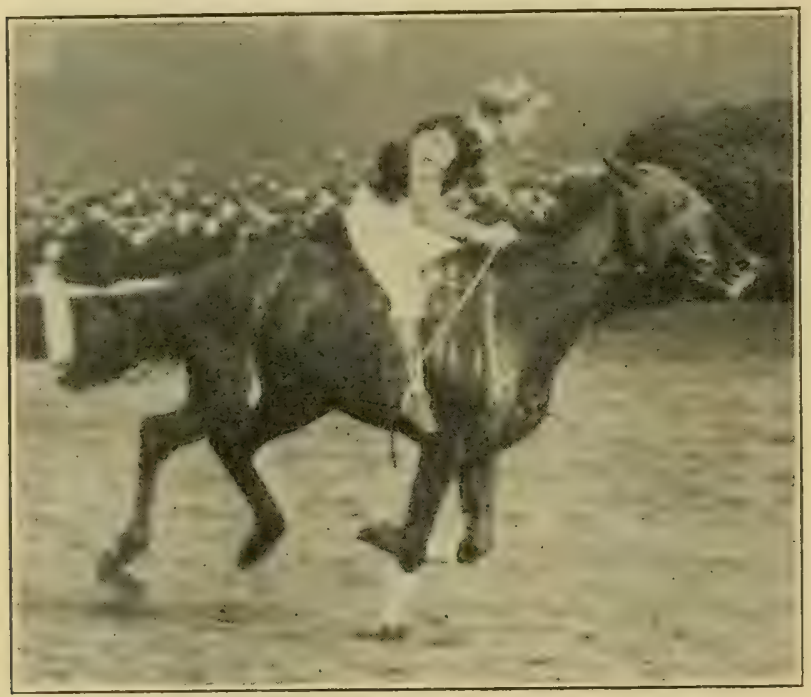

RACTNG GALLOP.

- lead, and that performance, which formerly was looked upon as a mere toiir de force of the masters, is now so well understood that no man with any pretention to horsemanship, should fail to demand it at any stride.

The gallop change was first described, and a photograph of the movement was first made public in the second edition of my "Modern Horsemanship" which was published in I 886.

The horse may change in the gallop in either of two ways. It may make the change in the order of the fore legs 
first, as they are freed from the ground, in which case there will be a false half-stride until the hind legs make the change. Or, more properly and safely, it may make the change com-

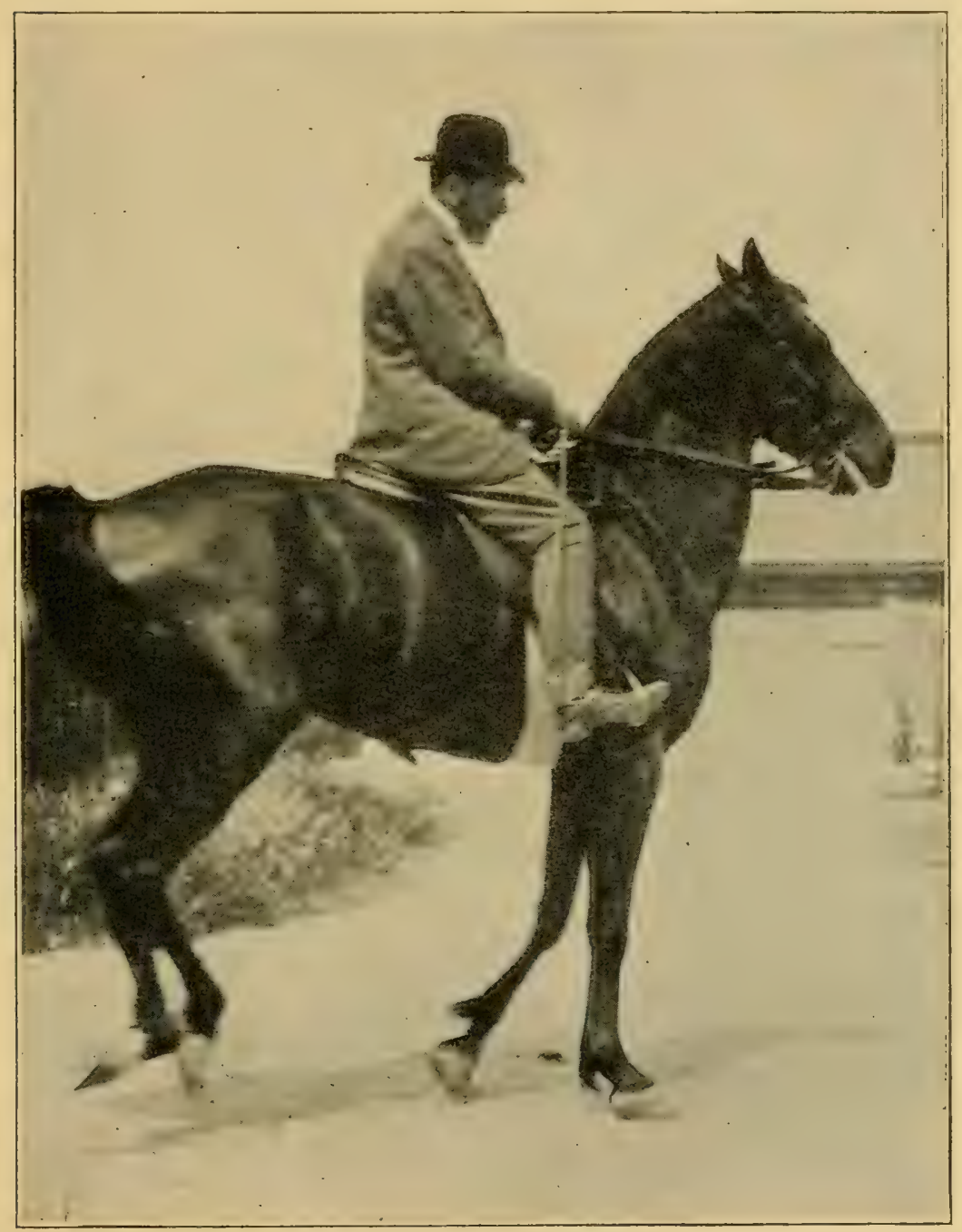

Gallop Change From Right to left.

(The right hind leg will next be planted.) Photograph by Mary Woods.

plete in one stride by changing the order of the hind legs as they are freed from the ground, beginning this change 
while the forehand has the weight of the mass; for after the forehand leaves the ground the hind legs are already committed to a certain stride. It is this latter mode that horseman require in changing lead, for in the turns and wheels the mass will then have a bearer under the centre of gravity.

Most horses can be taught the gallop change in a very

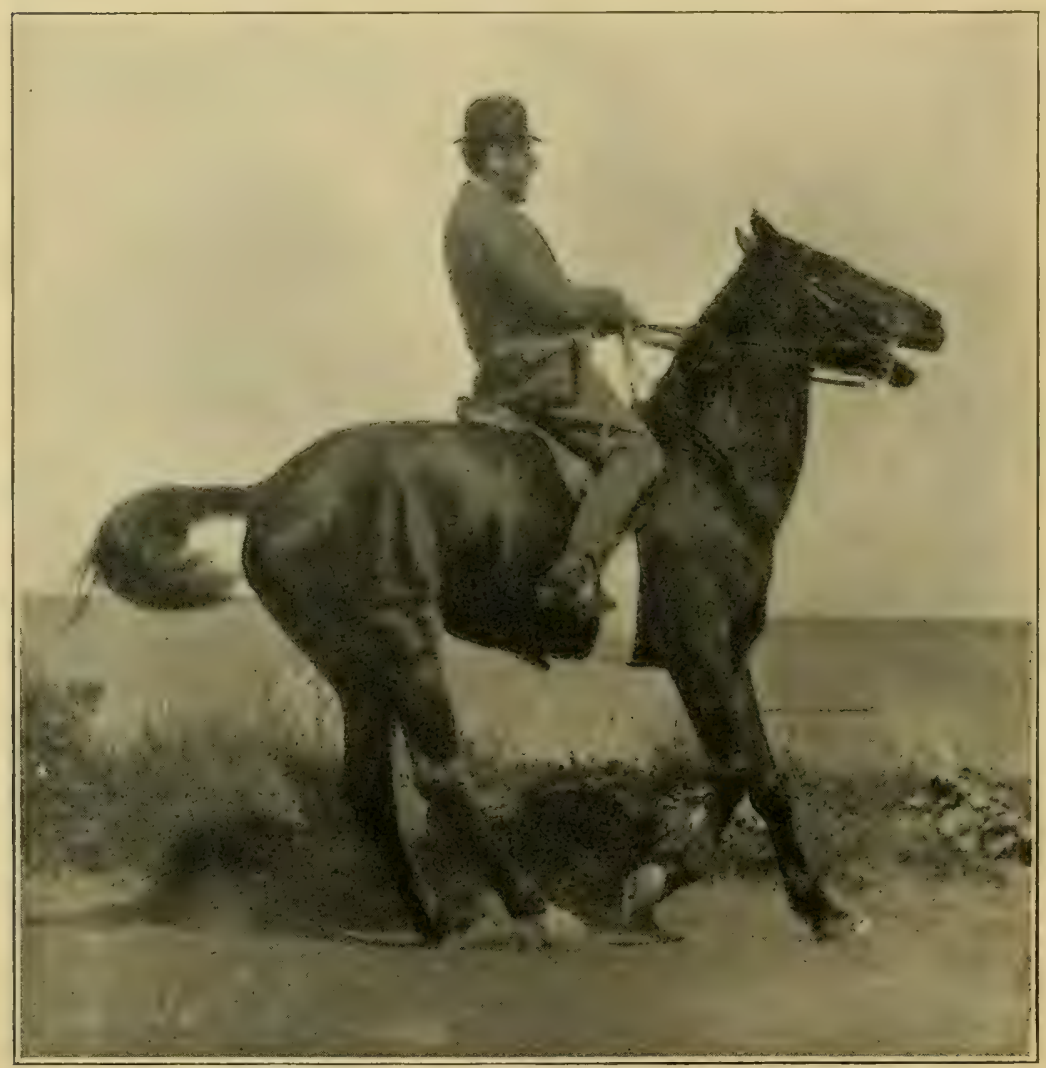

HALT IN GAILOP'STRIDE.

Photograph by Dorothy Woods

short time, the very high "steppers" only proving difficult, for the lower and more languid the action, the more readily the horse acquires the swing of the gallop change.

To teach the horse the changes of lead in the gallop, it must first be taught to take gallop right and gallop left with 
precision and composure. Then the man will put the horse in gallop right (or left) and after a dozen strides or so, bring it to a trot, and then demand the gallop left (or right).

Gradually the trotting steps should be eliminated, and the change be made during a half-halt; and, finally, the

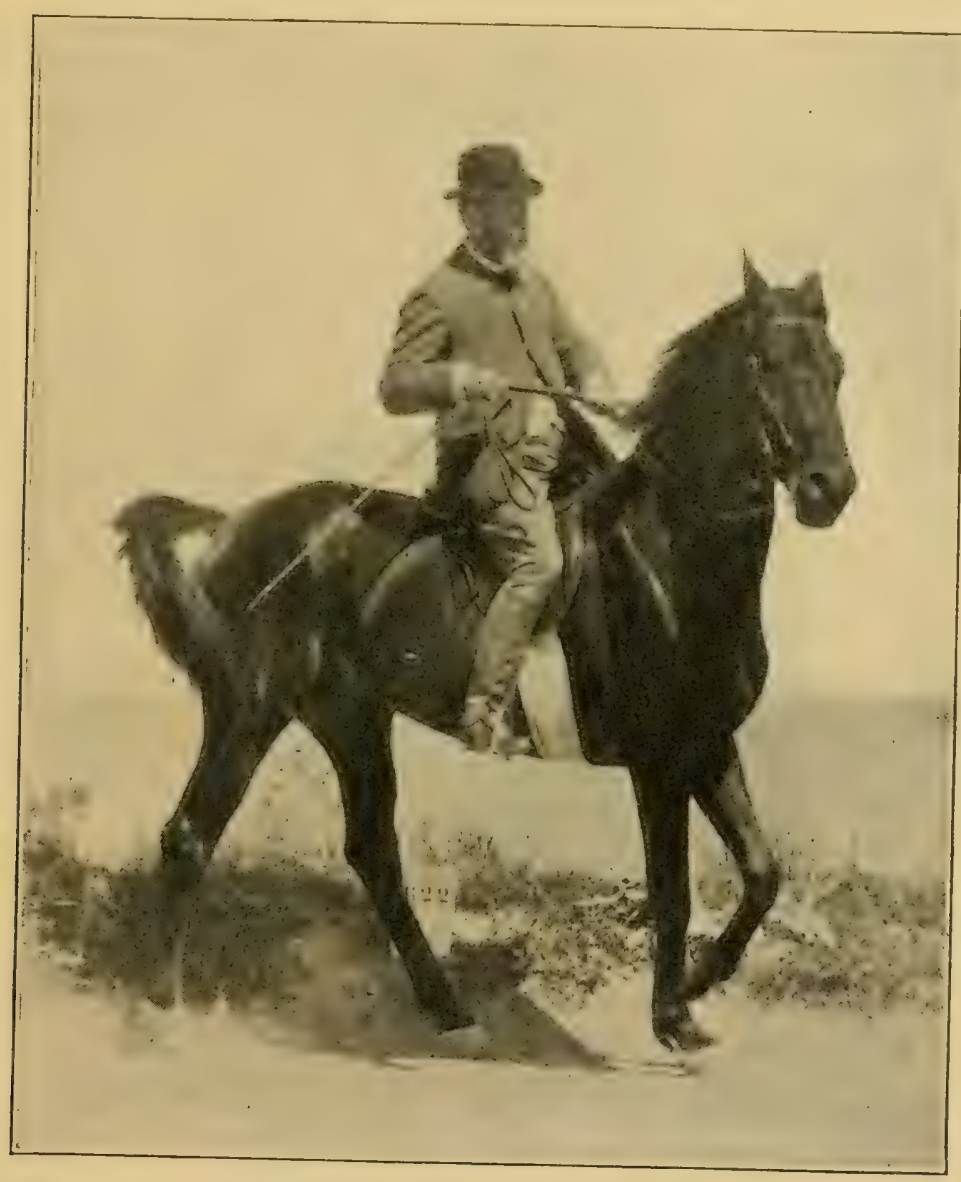

WhEel in GaLlop Right,

Photograph by Dorothy Woods.

half-halt should be unobserved, and the change be demanded in the beat of the pace. The speed must not be great, and the aids must be applied with quietness and exactness; the heel as the rearmost hind leg is leaving the ground, the rein 
giving an upward play as the forehand rises. That is to make the change from gallop right to gallop left, the right heel of the rider should give its effect as the left hind leg is leaving the ground and there should be a light upward play of the left rein as the forehand is about to rise, so that the left fore leg will be advanced. The change from gallop left to gallop right should be made in the same manner by means of the left heel and the right rein. The opposite heel and the opposite rein should, as in all other cases, govern and measure the effects of the acting heel and rein.

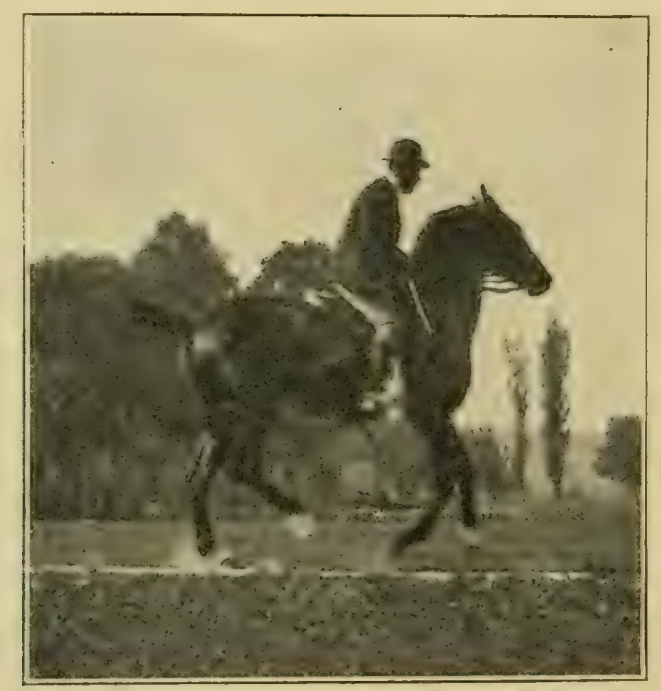

Gajlop Upon Two Paths to the Right.

(Anglo Normand, trained and ridden by the Author.)

Photograph by M. F. A.

To demand the halt in the gallop, the horse should first be taught to come to the stop by the pressure of the rider's heels and the raising of his hand as his body is bent backwards in the walk and in the trot. Then, in some gallop stride, as the forehand is dropping, the man should lean back, press his heels against the flank of the horse and raise his bridle hand, so that as the weight is taken upon the ad vanced fore leg the hind legs will go under the mass and check the momentum and the halt will be completed in one 
stride. A member of my family took a number of photographs as I halted "Charre" in the gallop, and all were successful representations of the movement. As may be understood, twenty-six years experience in photographing moving horses, have produced an expertness that it would be difficult to find in a professional photoghapher. Except in the gallop change we seldom have to repeat an experiment to obtain what is required, and in the picture representing the gallop change in this book, but one shot was taken. 


\section{CHAPTER IX.}

A CITIZEN'S DUTY TO RIDE. THE AUTOMOBILE AND THE AIR SHIP IN WAR.

It is the duty of every citizen, who is so situated that he can do so, to practice horsemanship, so that when called upon for the defense of his country he may be able to join a mounted corps, for even if all such appeared, we should not have too many mounted infantry and cavalry or trained artillery. The government should furnish good young horses at half the original cost to the trustworthy men, who will agree to serve in the militia regiments, the money thus expended to be returned to the purchaser in ten yearly installments. At the end of the ten years the militia-man should own the horse outright to do with it as he pleased; in the meantime the purchaser should have the horse for any proper use, on the farm or for draught, or riding pursoses, with the understanding that he and the horse shall appear for the annual drill and inspection. This is the method followed in Switzerland, and it works perfectly in a country not nearly so wealthy as ours, but composed of men so honest that no loss beyond reasonable wear and tear is borne by the tax payer, after the first cost. The Swiss army, I may say, is not only a model for all citizen soldiery, but is an effective force even in these days of advanced prepara. tion for the great cause.

The automobile may be of some service in the future as a draught engine in rear of troops; but for many reasons it will be of little or no service as an engine of attack, a few trenches across a road or some slight obstructions due to the topography of the country would render it useless. Of course, if a leader should array his troops upon a well kept, level lawn the squadrons of autos would make havoc among men and horses, and I have seen those protected machines, armed with quick firing guns, that might do some damage to men who would expose themselves. 
That the air ship may become a menace to border cities is already evident, but there must always be a limit to their powers and for a party to leave its base for any real distance in an air ship must prove the most disastrous end of all "forlorn hopes."

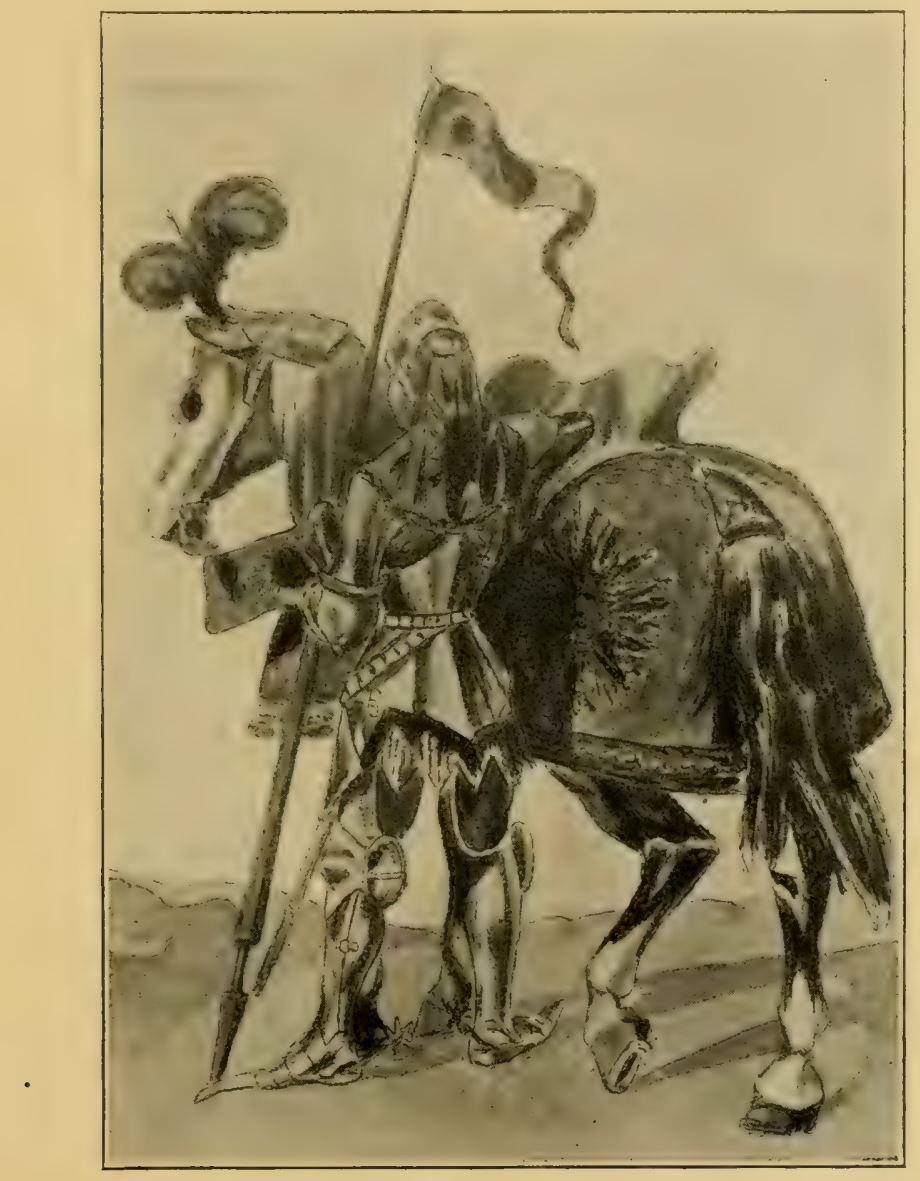

Man at arms. Time of Oharles Vil.

( The first enlisted Cavalry.)

Mary Woods d'apres de Noirmont.

So far from our having reached the age when mounted men can no longer be effective a little reflection should convince any one acquainted with the history of arms, that we 
are now entering upon an epoch when the horseman will hold a very important place in wars.

For thousands of years before cavalry appeared, the

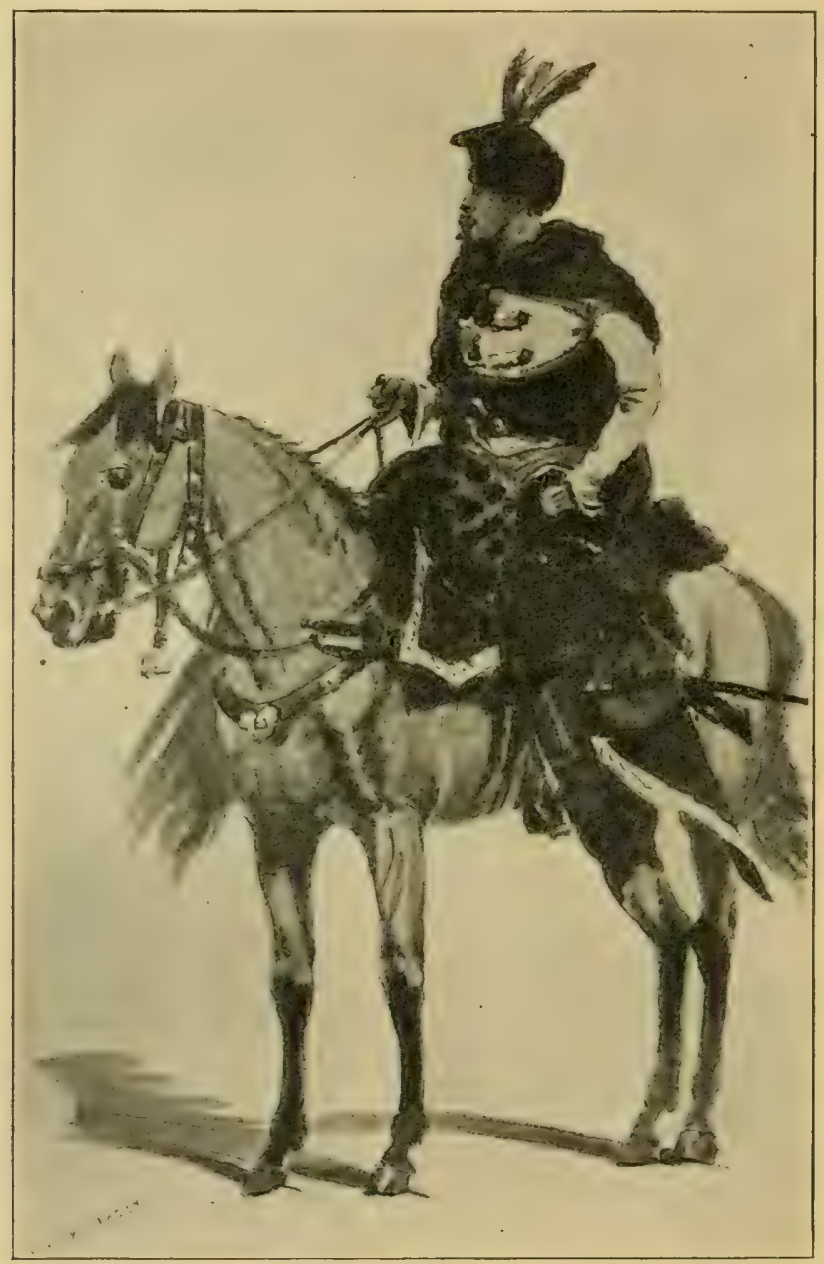

Estradiat. Moorish Plunderer. Time of Charleg Vill.

(The fore-runner of Light Cavalry.)

From an old print furnished by Hautecau, Paris.

horse was used for harness only; and the charge in battle was made by chariots. When, a few centuries before our era, the horseman came upon the scene (men without armor 
or clothed in leather, having no saddles beyond a cloth or a pelt) the frightful chariot with its scythe-armed wheels gradually fell into "harmless desuetude."

When complete steel armor was introduced, the knights had everything their own way, and unless some archer or pikeman found a break in the metal, a battle had for them little more danger than the present football match has for a player.

In August I I 19, a body of knights under Louis le Gros, King of France, met a similar band under Henry I, King of England, upon a beautiful plain near Rouen, and after contending through a long summer's day, could show only three men, hors du combat, smothered, likely enough, in their casques where they fell. In such battles the knights made up the list of prisoners for ransom, the archers, pikeman and varlets made up the roll of those who fell upon the field of glory.

The sword had its bright days in the early part of the seventeenth century, when such heroes as Gustavus Adolphus, Tilly, Wallenstein, Mansfeld, Christian of Brunswick, the pious Cardinals of Valette and Richelieu, and that splendid soldier of fortune de Gassion, used Europe as a chess board for their armies.

The Cuirassiers of that time had complete armor, and carried long blades that would do the work of an executioner. The Carabiniers, protected by the demi-cuirass, bore heavy flint lock arms, and the picturesque Mousquetaires were a sort of mounted infantry, while the dragoons were held only as light cavalry, and the advanced posts were watched by uncovered men on quick horses. But gun powder knocked off the armor and since then "Fitzjames's blade was sword and shield."

The arms of precision carry farther now than ever before should not lead any one to think that the days of cavalry, pure and simple are over. Forty years ago the rifle would kill at the distance of a mile and that did not prevent cavalry attacking infantry. Repeating arms increase the shower of projectiles and improved tactics decrease their peril. 
Believe me that the horsemen of our day and those of our descendents will charge with as much vigor and success as ever before. They will not be led across the fire swept plain, where perhaps every living thing would go down in the last thousand yards, but in war there will be always opportunties for horsemen, well led, to get in on their enemies with the sword or lance.

Finally, let me say, with Sir William Napier, that the soldier is one who offers his life for peace and protected homes. 


\section{CHAPTER X.}

RIDING SCHOOLS AND RIDING MASTERS. GOOD AND BAD

HORSES.

I have several editions of Baucher's method, among them a copy of the first, but it is really to the instruction of Henri Franconi that I owe my knowledge of the Master's theories. The writings of Fillis are clear, and any one should profit by them. Only the other day, I picked up a book in the shop of Legoupy of Paris, in which I found many things of interest, and I am ashamed to say that I cannot be certain of the name of the author, but what I wished to quote from, was that in describing the horse of the Midi the author warns his readers that the animal "must be treated like a gentleman." I have no sentimental feelings towards animals, but I deprecate cruel usage of those we have in our power, and such treatment is as useless as it is wrong. The spur and whip are to be employed as aids to carry the demands of the rider, but their applications are to be of the slightest character, and it is very seldom that the sharp rowel is required to touch the horse. Some of the foremost horsemen of Europe are very hard upon their horses, and they give a very bad example to those who admire their skill and courage. There are occasions when a sharp stroke of the whip may send a horse by an object that inspires its fear, but repeated blows will only irritate the animal and probably spoil it.

Writers upon horsemanship of the present day may congratulate themselves upon being clearer in their instructions than were their predecessors. Some persons pretend to understand Xenophon, soldier and statesman, whose work is the earliest extant, and whose instructions, so far as they are clear, are suitable to this day. But after an interval of two thousand years we come upon the Italian Pignatelli, that great teacher whose scholars carried the renaissance of the art throughout Europe, and whose writings are sufficiently obscure. Grisoni, whose book was printed in 1552 , 
and Count Fiaschis whose amusingly illustrated work saw the light four years later, could have been of no service. I have a copy of both books; that of Fiaschi's has prints in reproductions of pen and ink sketches under the figures of which are noted the songs the rider should sing to suggest the various movements. Pluvinel was the instructor of Louis XIII, and brought that Monarch to be one of the first horsemen of his day. Pluvinel's sumptuous work, with

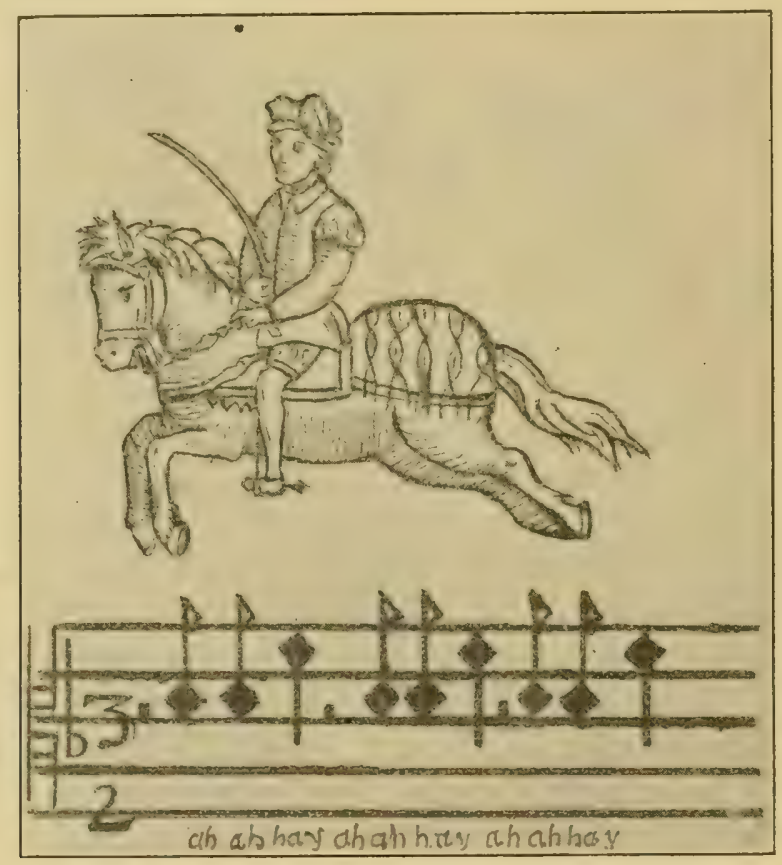

COT FROM COUNT FIASOHIS' WORK.

Count Frischi was a pupil of Piquetelli in 1550.

portraits of the King, was published in 1623 , and it is in appearance, the finest book that has ever appeared upon the subject. The work of de la Guérinière, one of the equerries of Louis $\mathrm{XV}$, is also a splendidly made volume published in 1733, with drawings by the court painter Parrocel. The Duke of Newcastle, after the defeat of the royal forces by Cromwell near York, went to the Continent and studied the 
art in the neighborhood of Paris. He was thought to excel all horsemen of his day, and his work on the training of the great horse, as the managed charger was called, had a great vogue. The first edition was issued from Antwerps in French, and many others followed. Previously many Englishmen had gone to the Continent to study the French method of schooling horses, among them the biographer of the pious Henry VIII, Lord Herbert of Cherbury, the nobleman who left his wife because she refused "to draw the

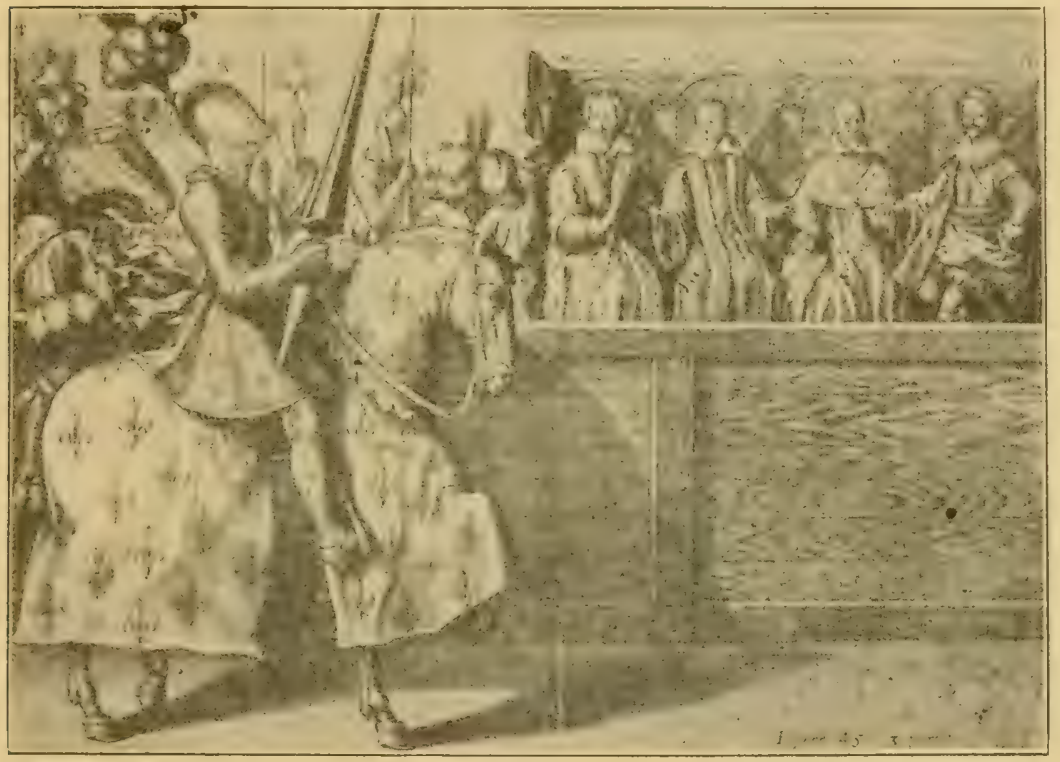

LoUIS XIII IN THE LISTS.

From Pluvenel's Work.

cradle over her head" by taking part of her fortune to make provisions for their heir. Henry VIII, by the way imported two of Pignatelli's pupils, but they left little impression upon the riding of their adopted country, and Newcastle was the last of the English who knew anything of horsemanship, as is witnessed by the writings of Lord Pembroke and of all who have followed them.

None of these old works are of any value, and Baucher's 
method which appeared about the middle of the last century, is the foundation of all that is good in the art, for even those who attack it show its value, and any reasonable man should recognize the importance of governing the horse through its instinctive yielding rather than by trusting to its good disposition.

Does it not seem senseless for men to ride badly for many years, in fact throughout the active parts of their

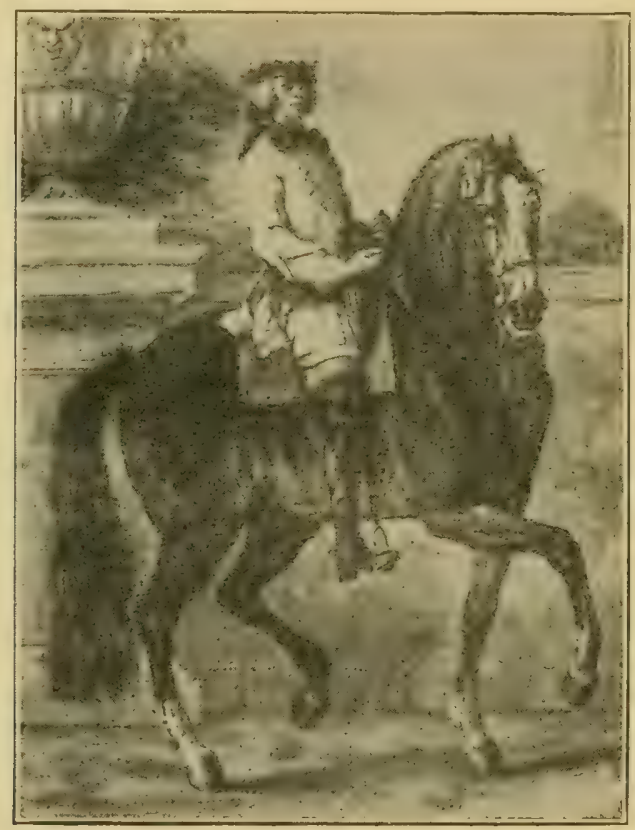

DE LA GUERINIERE。 1733.

( Equerry of Louis XV.)

From the Author's Work.

lives, when a little care and practice would make them fair, if not good, horsemen. There is a wide spread idea that the sportsman neglects all the refinements of horsemanship and follows the bounds at a breakneck speed on a horse whose training has only been over obstacles, and that kind of riding is considered good enough for pleasure or war.

The sportsmen of the Continent, French, German, Aus- 
trian, Belgian, etc., are as bold and as accomplished as any in England or in America, and have far greater knowledge of the training and management of the horse. They have, too, far more varieties of sport; although Punch and other such authorities have taught us that the continental sportsman is a weak and ridiculous creature. But the chase of the stag, the wolf, or the boar is no less manly than galloping over the grass or plough after a bagman imported from the low countries, or after an aniseed trail, not to mention the battues of farm bred pheasants which are not even indigenous.

In Europe, on the continent at least, horsemanship is considered as important a part of a gentleman's education as mathematics or grammar: and the course followed in the riding schools is long and thorough. After a man can sit the sauteur in a fairly violent effort, he is prepared to be confident and easy in any motion that a horse, untrained in that trying but artificial plunge, is likely to make, and ordinary jumping is afterwards mere child's play.

After an officer has passed two years in a continental riding academy he is either a finished horseman or his case is hopeless. The American who goes abroad to learn horsemanship, may have the same thorough training in several of the private schools which are superintended by those who give instruction exactly similar to that of the government schools, say that of Pellier or of Lefebore of Paris.

It is a great mistake to frighten recruits or beginners with horses and their ways. I take it that every man of normal intelligence fears the horse if unaccustomed to it. It is very difficult to restore confidence in the minds of those who are timid in the saddle, and it is not safe for such to ride, for the most stupid horse soon discovers whether or not it be the master and becomes a tyrant if it dare. It is not necessary to punish a horse to assert one's determina. tion. A composed manner and a firm course is the only way in which to obtain the real mastery over the animal. No one but an expert should undertake to dominate a vicious or a spoiled horse, but one that is simply fresh or gay needs work only to render it steady. The horse is an animal of simple ideas, and may often be turned from some mutiny or 
disorder by surprising it into a new train of thought. A fixed vice or trick can never be wholly eradicated. A good horseman may find no difficulty with an animal that has a vice or trick, but the moment it falls into the hands of an unready rider it will revert to its misconduct. It is impor. tant that the owner should know the ancestry of his horses, even of those of cold blood, and the history of the training and previous conduct of those he buys. It is better to pay a double price for a horse inscribed in the Kentucky saddlehorse stud-book than to get hold of an equally promising horse that has perhaps broncho blood in its veins. In France any horse fit for a gentleman's use is inscribed in some register, and we shall come to that in America in time. It certainly is not wise to acquire a horse that traces back to Ainser, a lunatic, to Boston, who transmits blindness, or to any one that had physical or mental defects. A little inquiry will nearly always prove to a purchaser whether he is looking at a horse of good or bad antecedents. 


\section{CHAPTER XI.}

UPON THE TREATMENT OF THE YOUNG HORSE.

It is not only the broncho, or range-horse that can make a buck jump. Any highly bred colt that has been permitted to run free until three or four years of age, when first taken up and saddled can and may plunge as violently as any "bad" horse from Wyoming. But, by a proper method of treatment, the domestic horse becomes amenable to discipline, and never or seldom makes any furious resistances after the first objections to restraint. The motion of the sauteur of the academies is as disturbing as it is possible for a pillared horse to make, but the wheels and motions of a free horse are undoubtedly more difficult to sit. There is one marked difference between the broncho and the domestic horse, due to "the call of the wild" as well as the method of training.

The former often submits only when it no longer has strength to struggle, while the latter usually recognizes the inevitable. Tight girthing and cruelty in many forms is undoubtedly answerable for much of the wickedness of the broncho, and the animal is passing away like the buffalo and other such forms on our continent, but for a long time we shall have enough of the blood in cheaply offered western horses. We have all heard the romantic story of the desert horse, which from its birth is treated as one of the family and never knows what liberty signifies. No doubt that is the proper method of rearing a horse but it is difficult to apply. If we take up a docile colt at a much later age we may correct the error by a systematic training, and have a perfectly satisfactory result, with probably a longer life of usefulness.

A farmer whom I know took up two colts "to break," one from its birth and one that was free until three years of age, both of the same strains, with the consequence that 
when the animals reached four years of age and upwards he could see no difference in their conduct.

The Swiss army being a militia, it is not required that all its officers, shall maintain horses, and in Thun is the Pferd Austalt where seven hundred high class chargers are kept on hand for sale or temporary use. Every year a large number of "remounts" are introduced and thoroughly trained under the supervision of Colonel Vigier von Steinbrugge. The annual increase of three year olds comes from the farms of Ireland, France, Hannover and Hungary, the latter being held in the highest esteem, and nearly all of these are

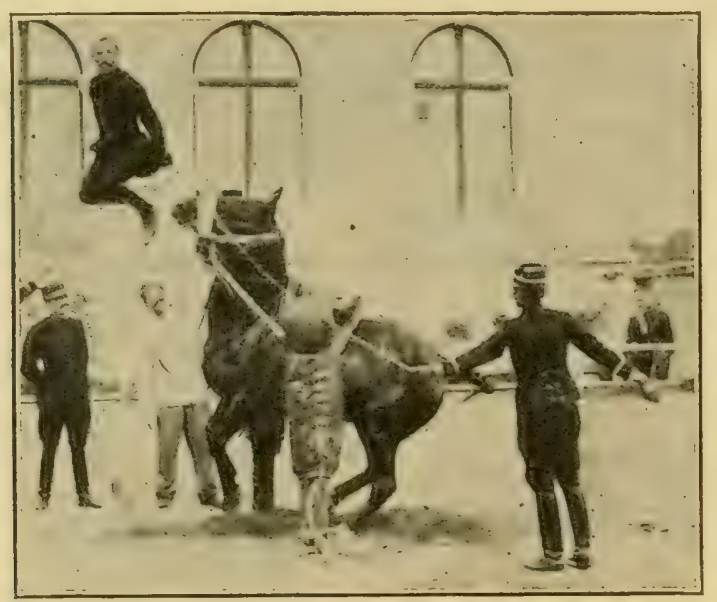

SAUTEUR. SAUMAR SUHoOL.

Photograph by H. Guionie, Saumar.

unbroken; the German horses being the most docile but the least resistant. Colonel Vigier, as the Swiss love to call him, is one of the finest riders in Europe, and it would be difficult to find any one who could supply his place in Thun, for he is not only the judge of all the horses selected for the establishment but he personally superintends their training, and it can be said of his success that of the hundreds of citizen soldiers who get horses from the Pferd Austalt no serious accident has ever happened through the misconduct of any of the horses. Colonel Vigier informed me that 
many of the three year olds were very violent in their resistances when first taken into hand, but that these game colts having given submission become perfectly docile and were the favorites of the men. It was one of his assistants, Major Schwendiman, who remarked to me that if he had to ride ten miles in haste he would select a thoroughbred, but that to ride around the world he would mount a horse from the Hungarian farm.

At whatever age the young horse is taken in hand, it should not be required to do any real work until it has became fully developed. Some horses are strong at five years of age, others due to the peculiarities of breed, or to their early neglect in the hands of the breeders, do not get their strength until six or seven years of age. The rule in the military services of Europe is to put the horse into the ranks at six years of age, when with care and without accidents, it should be serviceable for ten or twelve years.

Silvana, one of my horses, performed all the manege movements with grace and agility at twenty-five years of age, and many harness horses do good work up to the age of thirty years or even more.

At three years of age at latest, the young horse should be put upon the longe-line, or be driven before the trainer in a pair of long reins, to begin the discipline by which it is to be made obedient and serviceable. If it be put on the longe-line it should be made to pass about the man, to either hand equally at about the distance of fifteen feet. From time to time the colt should be brought to a halt and then be made to proceed, and it should be taught to change the direction of the movement. At first it might be better for the trainer to lead it, by holding the rein close to the head, in a circle of about thirty feet, and at no time should the horse be permitted to go more rapidly than a slow trot; after it passes at the full length of the line, a few pulls up and down on the line will act as a demand for reducing speed or for a halt. I always use the side lines from the mouth to the surcingle to keep the horse steady and to prevent the nose being thrust out too far. The man should never permit the horse to have a straight pull away from 
him, or the animal may get away and defeat his efforts to establish discipline.

If the trainer elects the long reins for the purpose of exercising the colt, the surcingle must have loops on either side, half way between the back and the belly, through which the reins must pass so that the horse may not make undesired turns towards the trainer. This driving the horse before the man on foot is excellent practice and may be used in connection with the work on the longe line. The horse should be longed or driven, for half an hour in the morning and for the same length of time in the afternoon. Great care should be taken not to give the horse fright, and it should be made accustomed to being handled in every

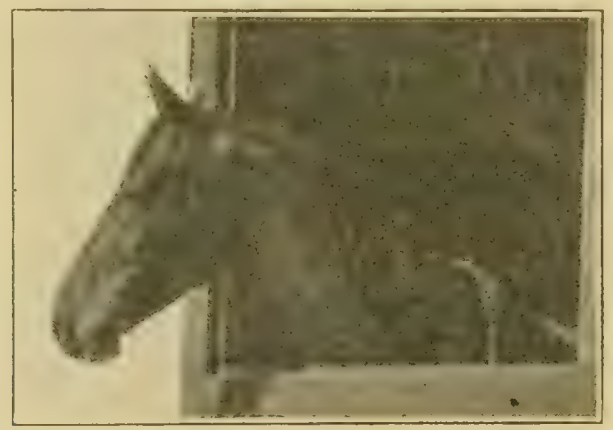

HEAD OF OIIARRE. ANGLO-ARAT3, QUAIIFIE.

Property of the Author.

part. When the horse has confidence in the man the lessons in leading on the longe or in driving by the reins may be given on the road to accustom the horse to the sights and sounds that it must hear in time.

If the trainer conducts these exercises with care and caution, there should be no difficulty in mounting the horse. A few lessons with the trainer on foot should be given to the horse saddled and bridled; the stirrups, in the earliest lessons looped up, afterwards permitted to dangle. Some day when there is no wind and no flies to disturb the horse, the trainer may quietly mount and let the horse move off a few steps and as quietly dismount. The mounted lessons should be 
increased in length very gradually, and the horse be taught to take hold of the bit and to bear the pressure of the rider's legs and the taps of the whip.

It. is much easier to give the first lessons in the company of an old steady horse; but the young horse will then for a long time expect society, and it often becomes restive and mutinous. I always prefer to train my horses in lonely places and usually I do not have even a groom. It is almost

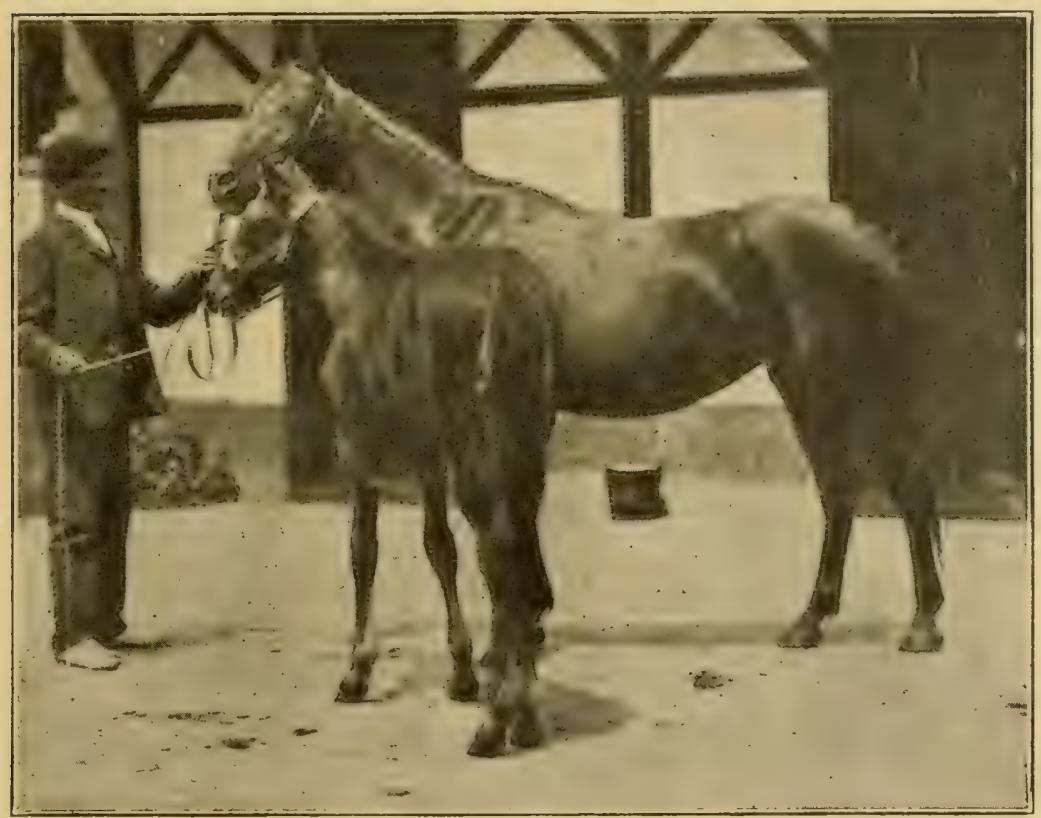

ARAB FoAL AND DAM.

Photograph by E. L. A.

useless to attempt giving lessons to a young horse in very severe weather, or when the flies and other insects are troublesome. In our climate, May and June, and October, November and December are the best months in which to begin work with young horses. If a covered manége is convenient, it should be used for the early exercises. When the horse is steady it should be ridden every other day in the open, be made to cross on the longe; or on the reins, over 
banks, walls, water and other obstacles, and have exercise sufficient to keep it in good condition.

One of the first lessons to be taught the young horse is to approach the trainer in answer to whip taps upon the chest. At first the horse will draw back and the taps should be applied until it moves forward freely, then the animal should be rewarded by a caress. In a very short time a horse will quickly respond to the touch of the whip, and even approach the man as he makes the motion of giving the tap. But in leading a. green horse, one not accustomed to obeying the whip, the man should walk either at the shoulder or in front of it; that is, he should not face the horse until it is so accustomed to him that he can do with it as he pleases. A horse well trained should be so complacent that an accidental blow or hurt should not disturb it. The only time I can remember giving Alidor a severe stroke with the spur, jwas in vaulting into the saddle at the gallop and I did not discover the injury by any movement of the horse. I have seen a nervous, sensitive, but highly trained thoroughbred receive a severe wound from an exploding shell without moving from its tracks.

The cavesson does not seem in as high favor at present as it was five and twenty years since, but neither are horses as well trained as they were in the past. At the same time I observe that those who are considered the best horsemen make liberal use of the cavesson in training young horses and in correcting the fault of those which have been spoiled.

There is no reason why anyone cannot learn how to train a horse thoroughly. One must study some good method and practice it as well as he is able. That there will be many mistakes and awkward situations at first is inevitable, but the rules are few and simple and in time any man can bring a horse up to the measure of his possible expertness. One must have no fear and "treat the horse like a gentleman," but he must insist upon the gentleman doing what is demanded. 





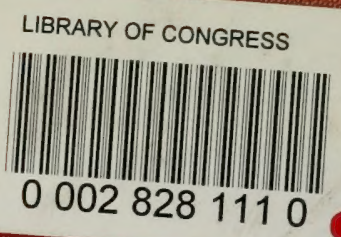

